\title{
LIMITED HANDLING QUALITIES EVALUATION OF AUGMENTED LONGITUDINAL FLIGHT CONTROL SYSTEMS DESIGNED WITH STATE- SPACE OPTIMIZATION TECHNIQUES (HAVE INFINITY)
}

PHILLIP T. EDWARDS

Captain, USAF

Project Manager

JANUARY 1997

FINAL REPORT

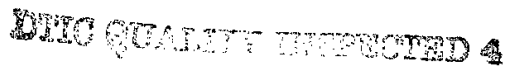

Approved for public release; distribution is unlimited.

AIR FORCE FLIGHT TEST CENTER EDWARDS AIR FORCE BASE, CALIFORNIA

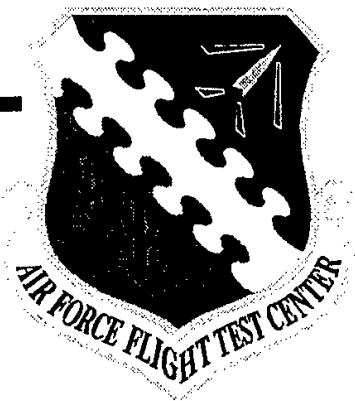


This technical report (AFFTC-TR-96-39, Limited Handling Qualities Evaluation of Augmented Longitudinal Flight Control Systems Designed With State-Space Optimization Techniques [HAVE INFINITY]) was submitted under Job Order Number M96J0200 by the Commandant, USAF Test Pilot School, Edwards Air Force Base, California 93524-6485.

Prepared by:

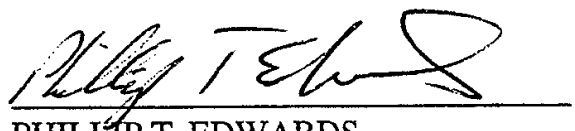

PHILLIP T. EDWARDS

Captain, USAF

Project Manager

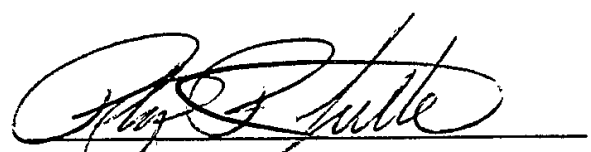

PHILPR. FITTANTE

Captain, USAF

Project Pilot

$\frac{\text { Thomas wiysyer }}{\text { THOMASW. YARGER }}$

Captain, USAF

Flight Test Weapons System Officer

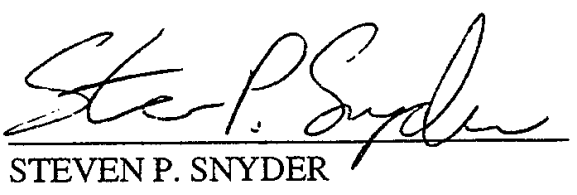

Captain, USAF

Flight Test Engineer

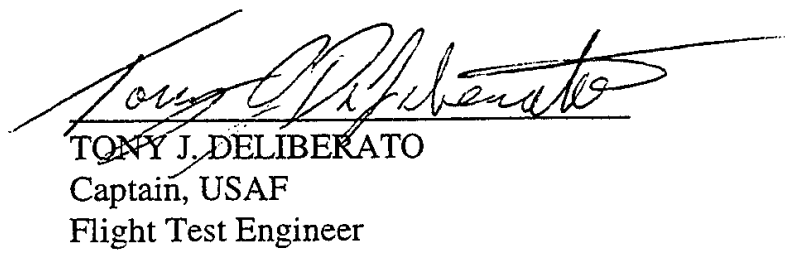

This report has been reviewed and is approved for publication: January 21, 1997
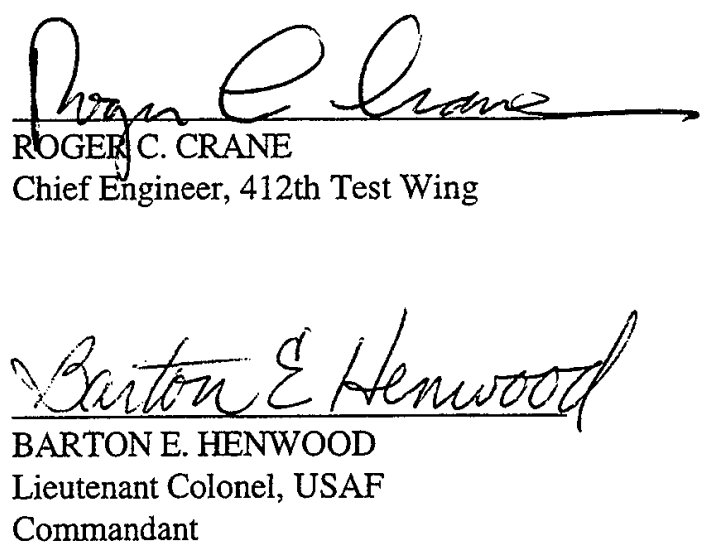


\section{DISCLAIMP NOTCL}

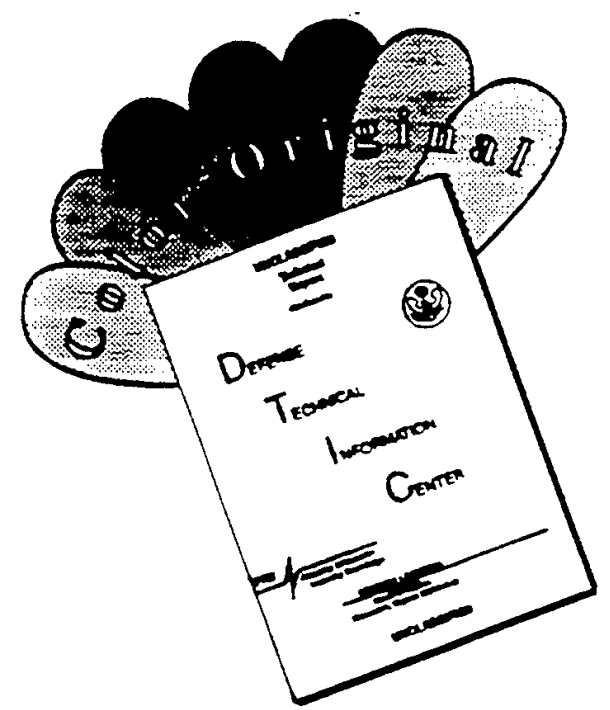

THIS DOCUMENT IS BEST QUALITY AVAILABLE. THE COPY FURNISHED TO DTIC CONTAINED A SIGNIFICANT NUMBER OF COLOR PAGES WHICH DO NOT REPRODUCE LEGIBLY ON BLACK AND WHITE MICROFICHE. 
Public reporting burden for the collection of information is estimated to average 1 hour per response, including the time for reviewing instructions, searching existing data sources, gathering and maintaining the data needed, and completing and reviewing the collection of information. Send comments regarding this burden estimate or any other aspect of this collection of information, including suggestions for reducing this burden, to Washington Headquarters Services, Directorate for information Operations and Reports, 1215 Jefferson Davis Highway, Suite 1204, Artington, VA 22202-4302, and to the Office of Management and Budget, Papenwork Reduction Project (0704-0188), Washington, DC 20503.

\begin{tabular}{|l|l|l}
\hline 1. AGENCY USE ONLY (Leave blank) & 2. REPORT DATE & 3. REPORT TYPE AND DATES COVERED
\end{tabular}

\begin{tabular}{|r|r|}
\hline January 1997 \\
\hline
\end{tabular}

4. TITLE AND SUBTITLE

Final, July to December 1996

Limited Handling Qualities Evaluation of Augmented Longitudinal Flight Control Systems Designed With State-Space Optimization Techniques (HAVE INFINITY)

6. AUTHOR(S)

Edwards, Phillip T., Captain, USAF

Fittante, Philip R., Captain, USAF

DeLiberato, Tony J., Captain, USAF Snyder, Steven P., Captain, USAF

Yarger, Thomas W., Captain, USAF

7. PERFORMING ORGANIZATION NAME(S) AND ADDRESS(ES

USAF TPS/EDA

220 S Wolfe Ave.

Edwards AFB CA 93524-6020

JON: M96J0200

PEC: $65807 \mathrm{~F}$

9. SPONSORING / MONITORING AGENCY NAME(S) AND ADDRESS(ES)

WL/FIGC

2210 Eighth Street, Bldg 146, Suite 21

Wright-Patterson AFB OH 45433-7531

8. PERFORMING ORGANIZATION REPORT NUMBER

AFFTC-TR-96-39

10. SPONSORING IMONITORING

AGENCY REPORT NUMBER

N/A

11. SUPPLEMENTARY NOTES

12a. DISTRIBUTION I AVAILABILITY STATEMENT 12b. DISTRIBUTION CODE

Approved for public release; distribution is unlimited.

A

13. ABSTRACT (Maximum 200 words)

This technical report presents the results of a limited handling qualities evaluation of augmented longitudinal flight control systems designed with state-space optimization techniques. The objective of the test was to evaluate the handling qualities of four longitudinal flight control systems during the approach and landing phase of flight. Three of the flight control systems used state-space design techniques and the fourth used classical design techniques. The four flight control systems were evaluated using the Variable Stability Simulator II (VSS II), which was a highly modified Learjet Model 25.

Testing was requested by Wright Laboratory, Wright-Patterson AFB, Ohio, and was conducted under the authority of the Commandant, USAF Test Pilot School.

14. SUBJECT TERMS handling qualities variable stability

landing tasks flight control systems

optimal control theory

state-space optimization techniques

17. SECURITY CLASSIFICATION
OF REPORT

UNCLASSIFIED

NSN 7540-01-280-5500

18. SECURITY CLASSIFICATION
OF THIS PAGE

UNCLASSIFIED

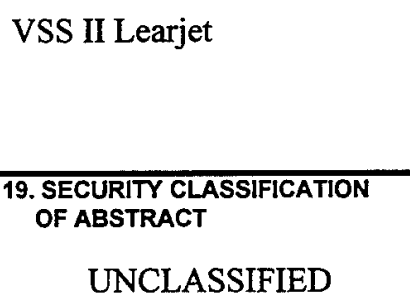

UNCLASSIFIED
15. NUMBER OF PAGES

\section{0}

16. PRICE CODE
20. LIMITATION OF ABSTRACT

SAR

Standard Form 298 (Rev. 2-89)

Prescribed by ANSI Std. Z39-18 298-102 
This page intentionally left blank. 


\section{PREFACE}

This technical report presents the results of a limited handling qualities evaluation of augmented longitudinal flight control systems designed with state-space optimization techniques (HAVE INFINITY). The handling qualities of four longitudinal flight control systems were evaluated during the approach and landing phase of flight. Three of the flight control systems used state-space design techniques and the fourth used classical design techniques.

Testing was requested by Wright Laboratory, Wright-Patterson AFB, Ohio, and was conducted under the authority of the Commandant, USAF Test Pilot School, Edwards AFB, California. The results of this test will be used to evaluate the practicality of using modern state-space techniques for flight control system design.

The HAVE INFINITY test team sincerely appreciates the assistance and contributions of several talented individuals. Foremost, we would like to thank Russ Easter and Scott Buethe of CALSPAN, without whom this flight test would have been impossible. 



\section{EXECUTIVE SUMMARY}

This technical report presents the results of a limited handling qualities evaluation of augmented longitudinal flight control systems designed with state-space optimization techniques. The objective of the test was to evaluate the handling qualities of four longitudinal flight control systems during the approach and landing phase of flight. Three of the flight control systems used state-space design techniques and the fourth used classical design techniques. The test objective was met.

The HAVE INFINITY test aircraft was the Variable Stability Simulator II (VSS II), which was a highly modified Learjet Model 25. The aircraft was operated by the Flight Research Department of the CALSPAN Advanced Technology Center. The four flight control system designs were implemented using the variable stability system of the VSS II aircraft.

Tests were conducted by members of the USAF Test Pilot School Class 96A from 30 September to 3 October 1996 at Edwards AFB and Palmdale Airport, California. Nine practice sorties were flown in the F-15, F-16, T-38, and C-23 aircraft. The actual test required six sorties in the VSS II, for 9 hours of flight time. Testing was requested by Wright Laboratory, Wright-Patterson AFB, Ohio.

Flight testing consisted of model validation and offset landing tasks performed in the VSS II aircraft.
Aircraft handling qualities were evaluated using the four different longitudinal flight control system designs. Cooper-Harper $(\mathrm{CH})$ and pilot induced oscillation (PIO) ratings were assigned by the project test pilots after each offset landing task. Specialized nunway markings and dedicated ground support personnel were used to accurately determine landing task performance. Analyses of $\mathrm{CH}$ and PIO ratings, as well as pilot comments, were used to determine a final handling quality level for each flight control system design.

Model validation testing revealed that the predicted designs did not match well with those implemented in the VSS II aircraft. However, recommendations were made to address this deficiency. The model validation inconsistencies cast doubt on the implementation and may impact accurate handling qualities ratings of these designs, but do not fully explain the undesirable characteristics exhibited on landing rollout. The designs, as implemented were evaluated for handling qualities. The three longitudinal flight control systems designed using state-space optimization techniques were determined to have Level III handling qualities. The classically designed longitudinal flight control system was determined to have Level II handling qualities. 
This page intentionally left blank. 


\section{TABLE OF CONTENTS}

Page No.

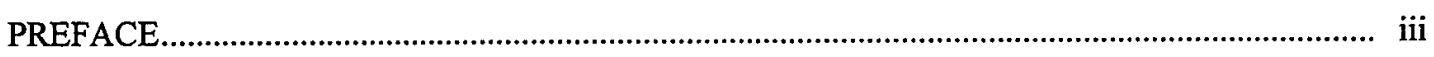



LIST OF ILLUSTRATIONS ................................................................................................... ix

LIST OF TABLES

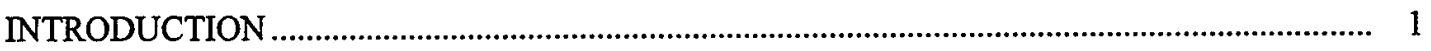

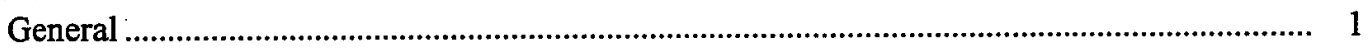

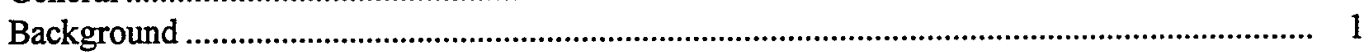

Test Item Description .....................................................................................................

Test Aircraft ...................................................................................................................... 1

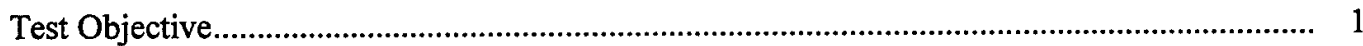

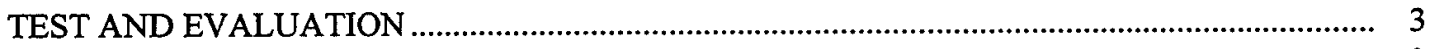

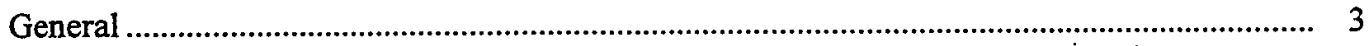

Methods and Conditions ......................................................................................................... 3

Test Procedures ..................................................................................................................... 3

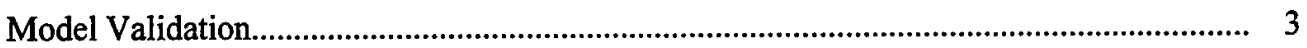

Offset Landing Task .......................................................................................................... 4

Landing Zone ............................................................................................................ 4

Landing Task Evaluation .................................................................................... 4

Results and Analyses ............................................................................................................ 4

Model Validation................................................................................................................ 4

Handling Quality Assessment ............................................................................................... 6

Classical Flight Control Configuration ....................................................................... 6

Noise Sensitivity Minimization Flight Control Configuration.................................... 6

Output Energy Minimization Flight Control Configuration ........................................ 6

Mixed Noise Sensitivity and Output Energy Minimization

Flight Control Configuration....................................................................................... 10

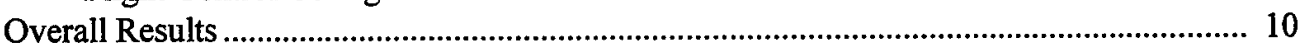

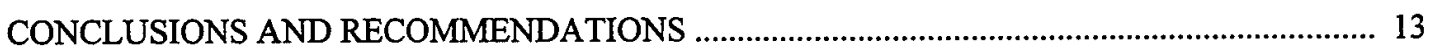

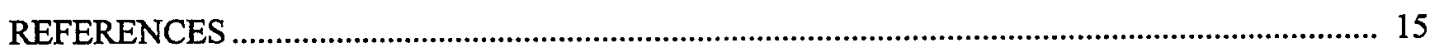

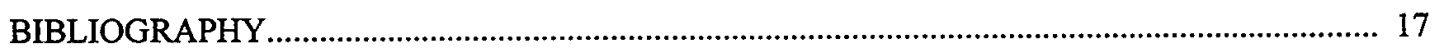



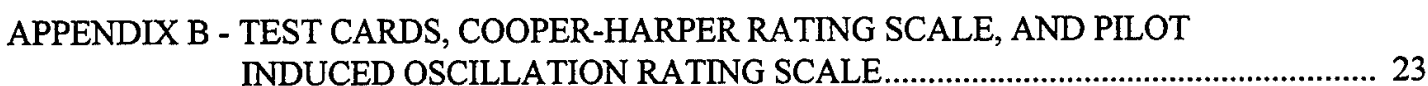

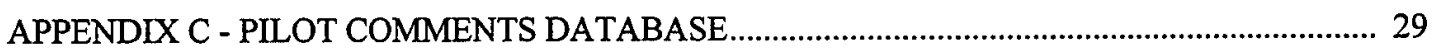






\section{TABLE OF CONTENTS (Concluded)}

APPENDIX E - DATA ANALYSIS PLOTS .




\section{LIST OF ILLUSTRATIONS}

Figure

Landing Zone Markings and Dimensions ……............................................. 5

Classical Flight Control Design Handling Quality Ratings................................... 7

Classical Flight Control Design Pilot Induced Oscillation Ratings........................ 7

$\mathrm{H}_{2}$ Flight Control Design Handling Quality Ratings....................................... 8

$\mathrm{H}_{2}$ Flight Control Design Pilot Induced Oscillation Ratings .................................. 8

$\mathrm{H}_{\infty}$ Flight Control Design Handling Quality Ratings .......................................... 9

$\mathrm{H}_{\infty}$ Flight Control Design Pilot Induced Oscillation Ratings............................... 9

Mixed Flight Control Design Handling Quality Ratings.................................... 10

Mixed Flight Control Design Pilot Induced Oscillation Ratings ........................... 11

\section{APPENDIX B}

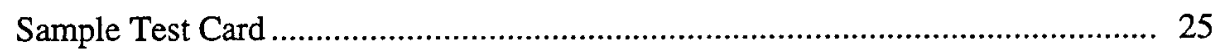

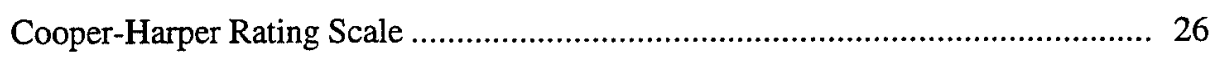

PIO Rating Scale Decision Tree ..................................................................... 27

\section{APPENDIX E}

Classical Design Bode Plot, Closed Loop, Alpha/PTI Sweep................................ 49

Classical Design Bode Plot, Closed Loop, Pitch Rate/PTI Sweep ......................... 50

$\mathrm{H}_{2}$ Design Bode Plot, Closed Loop, Alpha/PTI Sweep....................................... 51

$\mathrm{H}_{2}$ Design Bode Plot, Closed Loop, Pitch Rate/PTI Sweep ..................................... 52

$\mathrm{H}_{\infty}$ Design Bode Plot, Closed Loop, Alpha/PTI Sweep ..................................... 53

$\mathrm{H}_{\infty}$ Design Bode Plot, Closed Loop, Pitch Rate/PTI Sweep ................................... 54

Mixed Design Bode Plot, Closed Loop, Alpha/PTI Sweep..................................... 55

Mixed Design Bode Plot, Closed Loop, Pitch Rate/PTI Sweep .............................. 56

Step Input Time Histories, Classical Design ..................................................... 57

Step Input Time Histories, $\mathrm{H}_{2}$ Design ............................................................. 58

Step Input Time Histories, $\mathrm{H}_{\infty}$ Design ............................................................ 59






\section{LIST OF ILLUSTRATIONS (Concluded)}

$\underline{\text { Figure }}$

Title

Page No.

\section{APPENDIX F}

F1 Design Flight Control System Block Diagrams

63

F2 Variable Stability Simulator II (VSS II) Learjet Flight Control System Block Diagrams.

\section{LIST OF TABLES}

\section{APPENDIX A}

\section{APPENDIX D}




\section{INTRODUCTION}

\section{GENERAL}

This report presents the results of a limited handling qualities evaluation of four longitudinal flight control systems. Three of the flight control systems were designed using state-space optimization techniques (HAVE INFINITY). The fourth was designed using classical techniques. The purpose of the HAVE INFINITY flight test was to evaluate the handling qualities of these four longitudinal flight control systems during the approach and landing phase of flight. Flight tests were conducted using the CALSPAN Variable Stability Simulator II (VSS II) aircraft from 30 September to 3 October 1996 at Edwards AFB and Palmdale Airport, California. The HAVE INFINITY test team consisted of members of USAF Test Pilot School Class 96A. Team members flew 9 practice sorties, requiring 12 flight hours, and 6 test sorties, requiring 8 flight hours. Testing was requested by Wright Laboratory, Wright-Patterson $\mathrm{AFB}$, Ohio, and conducted under the authority of the Commandant, USAF Test Pilot School, Edwards AFB, California under Air Force Flight Test Center (AFFTC) Job Order Number M96J0200.

\section{BACKGROUND}

Classical root locus techniques have traditionally been used to design and refine highly augmented flight control systems. However, such techniques are difficult to use on systems with more than one input or output. In addition, several iterations of the flight control system have normally been required to optimize the design. State-space design techniques may be able to quickly and efficiently implement and refine highly augmented flight control systems. Noise sensitivity minimization $\left(\mathrm{H}_{2}\right)$ and output energy minimization $\left(\mathrm{H}_{\infty}\right)$ are state-space techniques that have been postulated for use in designing flight control systems. Implementations of the $\mathrm{H}_{2}$, the $\mathrm{H}_{\infty}$ and a mixed $\mathrm{H}_{2} / \mathrm{H}_{\infty}$ design were explored for potential benefit during this flight test. A classically designed flight control system was also tested for comparison.

\section{TEST ITEM DESCRIPTION}

The HAVE INFINITY test program consisted of four different longitudinal flight control configurations that were designed using different techniques. Three of the configurations were designed using state-space analyses. These were $\mathrm{H}_{2}$, $\mathrm{H}_{\infty}$, and a mixed design using $\mathrm{H}_{2} / \mathrm{H}_{\infty}$ For a discussion of these design techniques see References 1 through 4 . The fourth configuration used classical design techniques. See Appendix F for block diagrams of the flight control systems. The basic Learjet lateral directional flight control laws were used for all four configurations together with common control stick dynamics. The Bandwidth criteria (Reference 5) predicted marginal Level I handling qualities or better for each design. The R. Smith criteria (Reference 6) predicted Level II handling qualities and a pilot induced oscillation (PIO) rating of 1 for each design. The four flight control configurations were implemented and flown on the VSS II.

\section{Test Aircraft:}

The HAVE INFINITY testbed was the CALSPAN VSS II aircraft, tail number N102VS. The VSS II was a modified Learjet Model 25 that functioned as a three axis in-flight simulator. The cockpit had a set of side-by-side controls. The control yoke at the left seat, for the safety pilot, maintained the Learjet's conventional flight control system. The evaluation pilot's center control stick in the right seat used a fly-by-wire response feedback system. The variable stability and variable control system consisted of: variable feel system, aircraft motion sensors and associated signal conditioning, control system simulation computer, control surface servos, digital configuration control system, engage/disengage and safety monitor logic, and recording/playback capability. See Appendix A for a detailed description of the VSS II aircraft.

\section{TEST OBJECTIVE}

The test objective was to evaluate the handling qualities of the four HAVE INFINITY longitudinal flight control systems during the approach and landing phase of flight. Each flight control system was evaluated using an offset landing task as described in the Test Procedures section of this report. Cooper-Harper $(\mathrm{CH})$ and $\mathrm{PIO}$ ratings were 
assigned by the project test pilots after each offset landing task. Analyses of $\mathrm{CH}$ and PIO ratings, as well as pilot comments allowed the determination of a final handling quality level for each flight control system design. One of three levels was assigned based upon the following guidance:

Level I: Satisfactory, no improvement necessary, $\mathrm{CH} 1$ through 3;

Level II: Unsatisfactory but tolerable, deficiencies warrant improvement, $\mathrm{CH} 4$ through 6 ; and
Level III: Uñaccēp̄table, defíciencies require improvement, $\mathrm{CH} 7$ through 9.

These final criteria were based on information described in The Use of Pilot Ratings in the Evaluation of Aircraft Handling Qualities (Reference 7) and in USAF TPS Flying Qualities Phase Text Vol. IV, Flying Qualities Testing (Reference 6). 


\section{TEST AND EVALUATION ${ }^{-\cdots}$}

\section{GENERAL}

The HAVE INFINITY test program was conducted from 30 September to 3 October 1996 at Edwards AFB and Palmdale Airport, California. It consisted of six flights and 8 hours of flight test. The handling qualities of four different longitudinal flight control systems were evaluated during the approach and landing phase of flight using an offset landing task. The task was performed by four evaluation pilots with a broad range of flying experience. Table 1 summarizes each pilot's previous weapon system experience.

Table 1

EVALUATION PILOTS' FLYING EXPERIENCE

\begin{tabular}{|c|c|}
\hline $\begin{array}{c}\text { Evaluation } \\
\text { Pilot }\end{array}$ & Weapon System Experience \\
\hline \hline 1 & C-141B \\
\hline 2 & B-1B \\
\hline 3 & F-16 \\
\hline 4 & F-18 \\
\hline
\end{tabular}

Each of the four evaluation pilots rated the flight control system designs using the $\mathrm{CH}$ and PIO rating scales (Appendix B). Prior to the actual flight test, each pilot practiced the offset landing task in a variety of different aircraft. This allowed the pilots to become familiar with the task over a broad range of aircraft handling qualities. The practice aircraft included the F-15, F-16, T-38, and C-23.

\section{METHODS AND CONDITIONS}

All four flight control system designs were evaluated by CALSPAN and the HAVE INFINITY test team using the VSS II ground simulation mode prior to flight. In addition, two verification flights were flown by a CALSPAN safety pilot and a USAF Test Pilot School staff pilot prior to actual flight test of the designs. Flight tests were limited to a maximum headwind of 20 knots, a maximum tailwind of 10 knots, and a maximum crosswind of 10 knots for flight safety and data quality considerations.

The test team aircrew onboard the VSS II included a CALSPAN safety pilot, a HAVE INFINITY evaluation pilot, a test conductor, and a CALSPAN system operator who reconfigured the flight control systems. The CALSPAN safety pilot was aircraft commander. The test conductor duties were performed by a HAVE INFINITY test team engineer or a second evaluation pilot. The ground test team consisted of two spotters stationed beside the landing runway at Palmdale Airport. These spotters maintained VHF radio contact with both the Palmdale control tower and the test team aircrew.

The flight test was structured into test blocks. Each test block represented one of the four flight control system configurations and consisted of three approaches. The three approaches had to be flown sequentially on a single flight in order to complete the test block. Each test block was reserved for a single pilot/flight control configuration pairing. Only the CALSPAN safety pilot and the test conductor knew which flight control system was actually being tested. Evaluation pilots performed blind testing throughout the test program.

The first approach of each test block was a straight-in to a touch and go. If the flight control configuration under test was controllable, as defined in MIL-STD-1797A (Reference 5), the test proceeded to the offset landing task. The offset landings were accomplished as described in the Test Procedures section. The evaluation pilot provided comments and $\mathrm{CH} / \mathrm{PIO}$ ratings for each offset landing performed. If a $\mathrm{CH}$ rating of 8 or better was obtained on the first offset landing of a test block, the evaluation pilot repeated the offset landing task and again provide comments and $\mathrm{CH} / \mathrm{PIO}$ ratings. $\mathrm{A}$ third offset landing was accomplished if the comments and ratings from the first two were inconsistent. The test conductor determined if the ratings were consistent and when the test block was complete. Data from any additional landings were also included in the final analysis of the appropriate control system design.

\section{TEST PROCEDURES}

\section{Model Validation:}

Model validation testing was accomplished on the four flight control system designs while flying to and from Palmdale Airport. Only one design was examined on a single sortie. Heavyweight data were 
obtained flying to Palmdale Airport and lightweight data during the return trip to Edwards AFB. Programmed Test Inputs (PTI) provided the required frequency sweeps and step inputs. The frequency sweeps provided data for frequency response analyses (FRA). Data were recorded using the VSS II onboard system in a MATLAB ${ }^{\circledR}$ format. The sampling rate was $50 \mathrm{~Hz}$. Recorded data parameters are listed in Table D1. All model validation testing occurred between 4,000 and 6,000 feet MSL. The aircraft was flown at final approach speed (125 to $135 \mathrm{KAS}$ ) with gear down and 20-degree flaps. The frequency range of the programmed sweeps was from 0.1 to $10 \mathrm{~Hz}$. The amplitude was 0.25 degree. Duration was 25 seconds which provided approximately 1,250 data points. The FRA was performed using PC-FRA, Version 1.01, developed by High Planes Engineering. Step inputs were used to compare predicted time histories. The steps were 1 inch of stick deflection in magnitude for 3 seconds duration. Time histories and bode plots were then compared to predicted responses simulated in MATLAB ${ }^{\circledast}$.

\section{Offset Landing Task:}

The offset landing task was performed at Palmdale Airport, Runway 25. The VSS II aircraft was configured with the appropriate flight control system on downwind at approximately $150 \mathrm{KCAS}$ and the variable stability system was then engaged. The aircraft was configured with gear and 20-degree flaps and turned to final to intercept the 3-degree ILS glideslope. On final, the aircraft was offset 300 feet to the left of centerline and slowed to final approach speed. The safety pilot called altitude above the ground in 50-foot increments off of the radar altimeter. At 200 feet above ground level (AGL), the safety pilot called "maneuver". The evaluation pilot aggressively maneuvered the aircraft using 30 to 45 degrees of bank to capture the runway centerline. A simultaneous longitudinal correction was made to intercept a visual glidepath to touchdown. The pilot attempted to land in the middle of the desired box described in the next paragraph at a touchdown speed 10 knots less than approach speed (+10/-5 knots).

\section{Landing Zone.}

Specialized runway markings used to determine desired and adequate task performance were painted on Runway 25 at Palmdale Airport. Standard 18-inch wide white paint lines were used for all markings. The landing zone markings are depicted in Figure 1. The leading edge of the desired box corresponded to the ILS glideslope point of impact. Standard runway distance markers were used as a backup in case the lines became obscured or a runway change was necessary.

\section{Landing Task Evaluation.}

Following the touch and go, the safety pilot took control of the aircraft. The evaluation pilot received a performance rating from the ground spotters over the VHF radio based on the aircraft's touchdown position. For a landing to be considered in a particular zone, both main landing gear were required to be on or inside the respective white line. The evaluation pilot determined whether airspeed and lateral touchdown criteria were met. Based on this information, the evaluation pilot assigned a performance rating of desired, adequate, or inadequate. The test conductor then stepped the evaluation pilot through the $\mathrm{CH}$ and PIO rating scales. Evaluation pilots assigned a $\mathrm{CH}$ and $\mathrm{PIO}$ rating to each offset landing task accomplished. Evaluation pilots also gave qualitative comments on handling qualities, workload, and problems effecting task performance. The comment card used is shown in Appendix B.

An $8 \mathrm{~mm}$ camcorder onboard the VSS II recorded all landings and associated pilot comments. A ground-based camera also recorded Sortie No. 2 from final approach to rollout. Postflight analyses of cockpit videotape and the test card comments was used to construct a database of pilot comments for each of the four flight control system designs. A summary of these pilot comments can be found in Appendix C.

\section{RESULTS AND ANALYSES}

\section{Model Validation:}

Model validation analyses was performed using the data shown in Appendix E. Block diagrams of the flight control systems modeled are presented in Appendix F. Bode plots generated from MATLAB ${ }^{\circledR}$ and flight test data for the closed-loop transfer functions alpha output to stick displacement and pitch rate output to stick displacement were analyzed for each design method. The flight test 


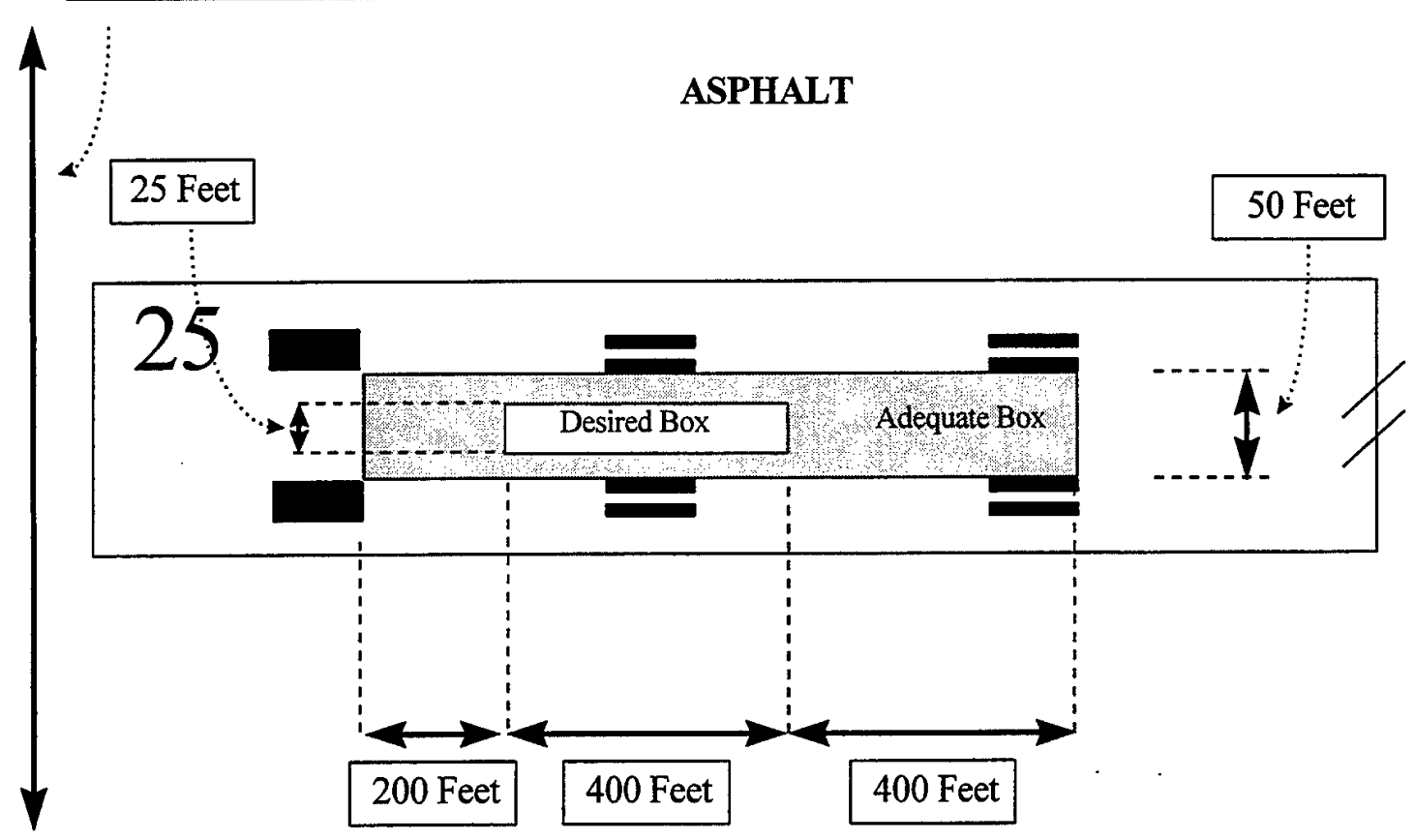

Figure 1 Landing Zone Markings and Dimensions

data were limited in frequency range from 0.1 radians per second to approximately 30 to 40 radians per second, based on the frequency sweep used. The higher frequency content was not considered significant since this was beyond the frequency range that affects handling qualities and most of the system outputs in the flight control systems were attenuated above 30 radians per second. Lower frequency data would be desired, down to at least 0.01 radians per second, to validate the low frequency response of the closed-loop system and to compare it to the predicted model since there were some dynamics predicted at lower frequencies. Model validation testing should be conducted with frequency sweeps that provide a lower frequency content. $(\mathrm{R} 3)^{1}$

For the classical flight control system design, the magnitude gain over the frequency range tested matched well with predicted values. The $\mathrm{H}_{2}$ design frequency plots showed significant differences between the predicted gain levels and the flight test data. The $\mathrm{H}_{\infty}$ design frequency plots were

\footnotetext{
${ }^{1}$ Numerals preceded by an " $R$ " within parentheses at the end of a paragraph correspond to the recommendation numbers tabulated in the Conclusions and Recommendations section of this report.
}

inconclusive due to scatter, and were marginal at best. The mixed design frequency plots had the best comparison with the predicted model, but still contained some additional gain above 10 radians per second. The phase content of the closed-loop system, for all the designs, consistently showed additional phase lag, as much as approximately 20 degrees from predicted. This could degrade the predicted handling qualities, based on Ralph Smith criteria, as much as one to two $\mathrm{CH}$ ratings (Reference 8 ).

Flight test time histories of alpha and pitch rate (q) resulting from a step PTI were compared to MATLAB $^{\circledR}$ generated model predictions (Figures E9 through E12). The predictions used a 3-second step input, while the duration of the PTI lasted from 5 to 6 seconds. Response trend comparisons could still be made. The flight test pitch rate response was representative of the predicted response for all the designs except the $\mathrm{H}_{2}$ design, which deviated from predicted. The classical and the mixed designs exhibited some additional pitch rate response delay, compared to the predicted model. The alpha flight test response for all the designs was similar in character to predicted for the first 1 to 2 seconds, although the classical design displayed more initial 
delay. The alpha response had significant deviations which can be seen in Figures E9 through E12.

The close matches between the classical predicted curves and the flight test data, for both frequency response and time histories, tend to indicate that the unaugmented aerodynamics simulated by the VSS II Learjet were similar to the model used in design, although the classical system exhibited significant additional lag. This in-flight simulated aerodynamic model was used for all the configurations flown. The marginal at best (mixed), inconclusive to unacceptable $\left(\mathrm{H}_{\infty}\right)$, and completely mismatched $\left(\mathrm{H}_{2}\right)$ comparisons between predicted curves and flight test data indicate a problem in the implementation of these designs in the VSS II Learjet. Analyses of the VSS II Learjet system capabilities and the limitations when implementing these flight control designs are beyond the scope of this report, but should be considered in future flight tests of similar systems. Furthermore, these factors may contribute to but do not fully explain the undesirable aircraft response during the flare through landing rollout, exhibited by some of the flight control systems described in the following results sections. Further analyses on the VSS II Learjet system and its limitations when implementing flight control system designs should be conducted to ensure proper configuration setup. (R1)

\section{Handling Quality Assessment:}

\section{Classical Flight Control Configuration.}

The four evaluation pilots performed four straight-in approaches and nine offset landing tasks with the classical flight control design. See Figures 2 and 3 for $\mathrm{CH}$ and PIO ratings. All the pilots stated that the classical flight control design flew nicely throughout the landing task. The aircraft was predictable, responsive and had good sensitivity. One pilot indicated that quick abrupt inputs were required to maintain glidepath, and that there was a tendency to over flare the aircraft. A second pilot stated that he got a slight bobble upon the initial glideslope capture and that the stick was a bit too heavy. The third pilot stated that excessive aft stick was required in the flare. A fourth pilot stated that the aircraft flew nicely without additional qualifications. Overall, this configuration was considered Level II.

\section{Noise Sénsifivity Minimization Flight Control Configuration.}

The 4 evaluation pilots performed 4 straight-in approaches and 11 offset landing tasks with the $\mathrm{H}_{2}$ flight control design. See Figures 4 and 5 for $\mathrm{CH}$ and PIO ratings. The comments indicated that the aircraft felt heavy and unresponsive. One pilot called the aircraft jittery. The aircraft required low gain inputs in order to fly acceptably. Of the 11 landings, 8 had desired touchdown performance, 1 had adequate, 1 was inadequate, and 1 was not performed properly. All pilots indicated that the aircraft was acceptably flown down to touchdown. The aircraft exhibited an uncommanded noseup after touchdown requiring extensive forward stick input to maintain control. On one occasion the aircraft became unexpectedly airborne after touchdown. The aircraft performance after touchdown drove the higher $\mathrm{CH}$ ratings. Overall, the $\mathrm{H}_{2}$ flight control configuration was considered to have Level III handling qualities due to the unacceptable motions after touchdown.

\section{Output Energy Minimization Flight Control Configuration.}

The 4 evaluation pilots performed 5 straight-in approaches and 13 offset landing tasks with the $\mathrm{H}_{\infty}$ flight control design. See Figures 6 and 7 for $\mathrm{CH}$ and PIO ratings. The comments indicated that the aircraft flew predictably until the pilot increased his input gains when the aircraft exhibited a jittery motion. Of the 13 landings, 7 had desired touchdown performance, 4 were adequate, and 2 were inadequate. One pilot noticed a lightening in control forces with reduction in airspeed for all four of his landings. For all pilots the aircraft behaved unpredictably upon flare initiation. The aircraft tended to float and all pilots noted the need to apply forward stick right after the initiation of the flare to arrest the pitchup motion. After the main gear touchdown, the nose could not be lowered even with full forward stick input. On at least one occasion the aircraft unintentionally ballooned and became airborne after touchdown. The aircraft performance after the initiation of the flare through landing rollout resulted in the high $\mathrm{CH}$ ratings. Overall, the $\mathrm{H}_{\infty}$ flight control configuration was considered to have Level III handling qualities due to the unacceptable motions after the flare initiation through landing rollout. 




Figure 2 Classical Flight Control Design Handling Quality Ratings

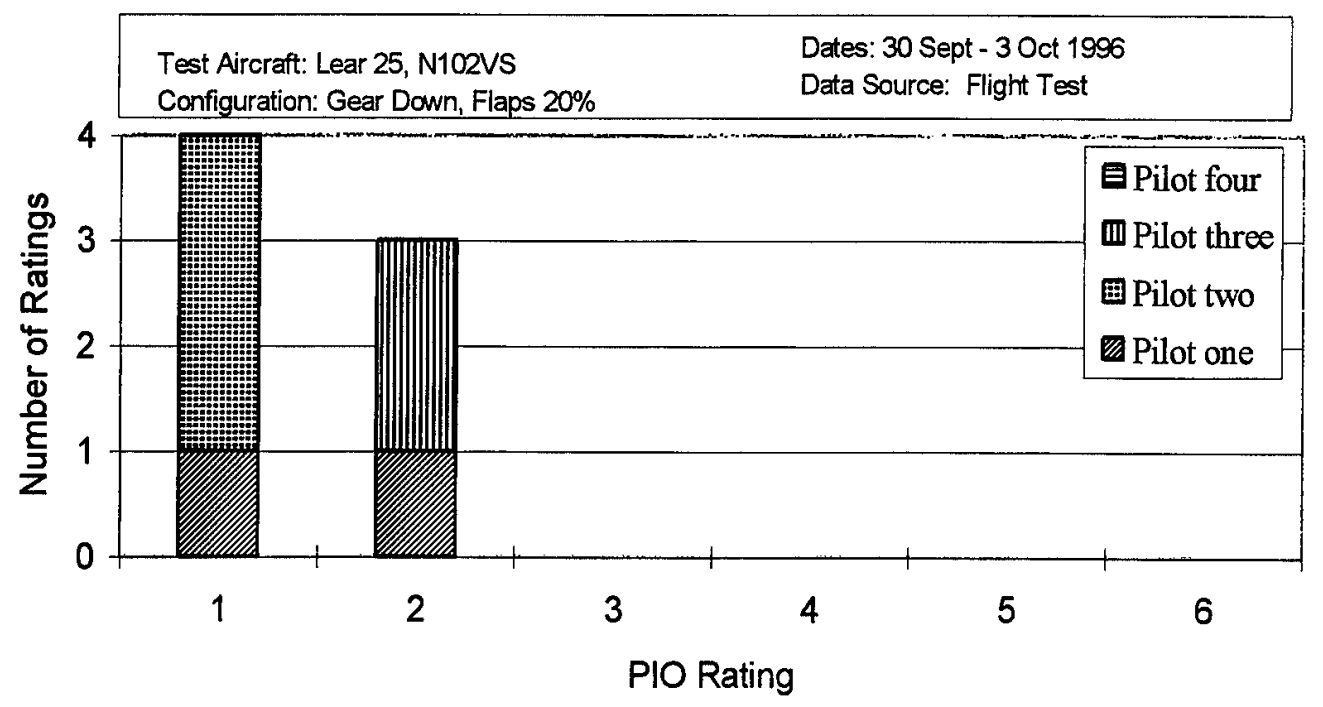

Figure 3 Classical Flight Control Design Pilot Induced Oscillation Ratings 


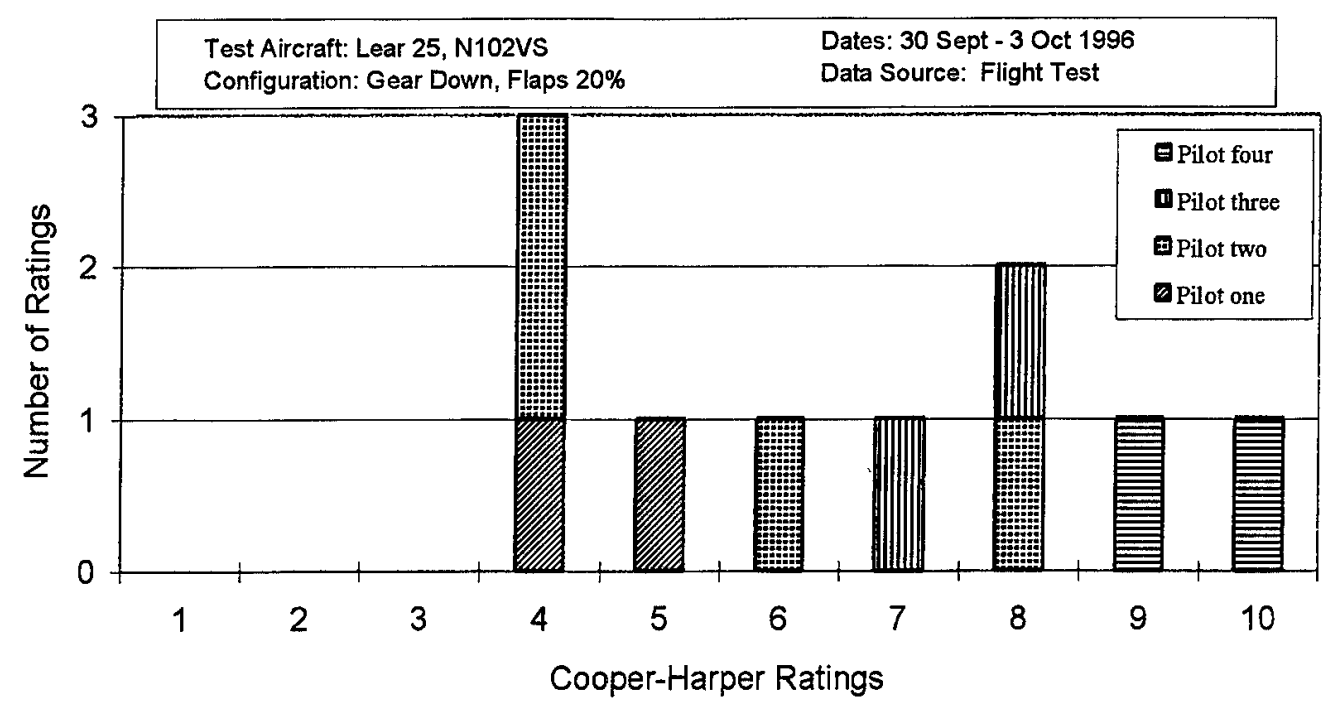

Figure $4 \mathrm{H}_{2}$ Flight Control Design Handling Quality Ratings



Figure $5 \mathrm{H}_{2}$ Flight Control Design Pilot Induced Oscillation Ratings 


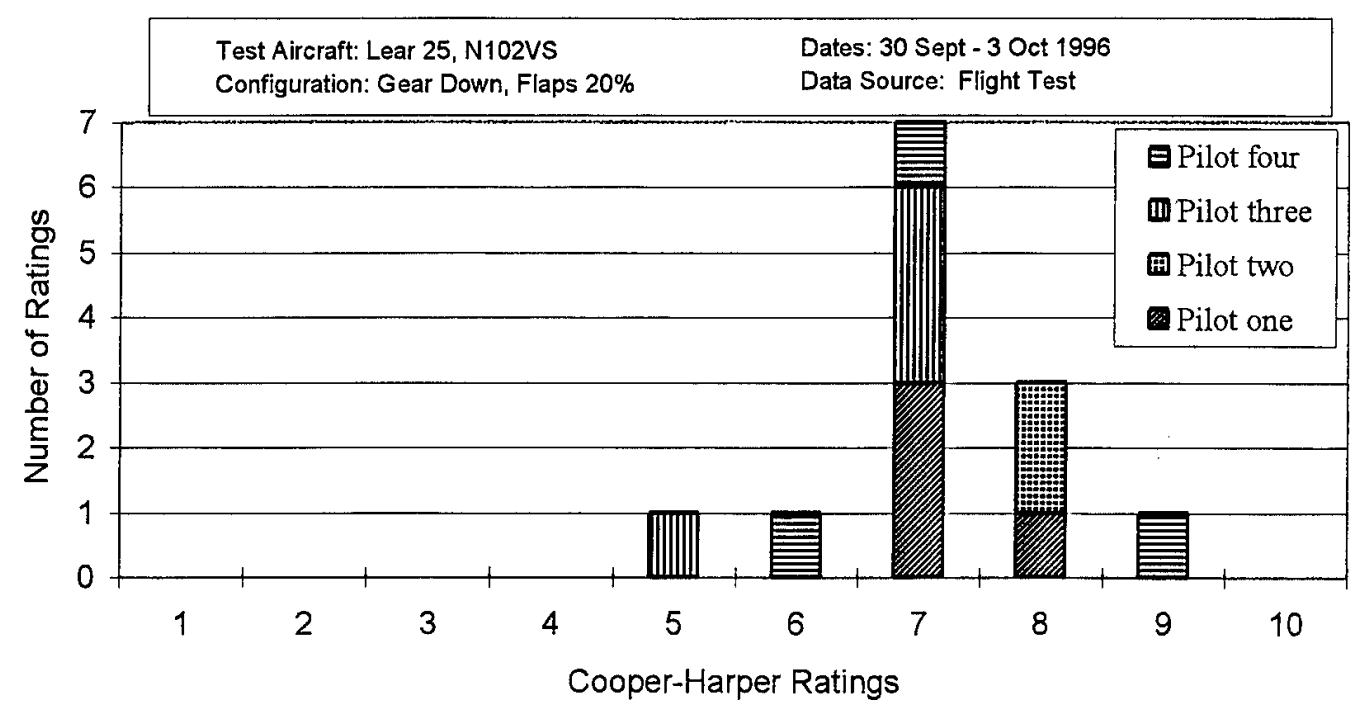

Figure $6 \mathrm{H}_{\infty}$ Flight Control Design Handling Quality Ratings

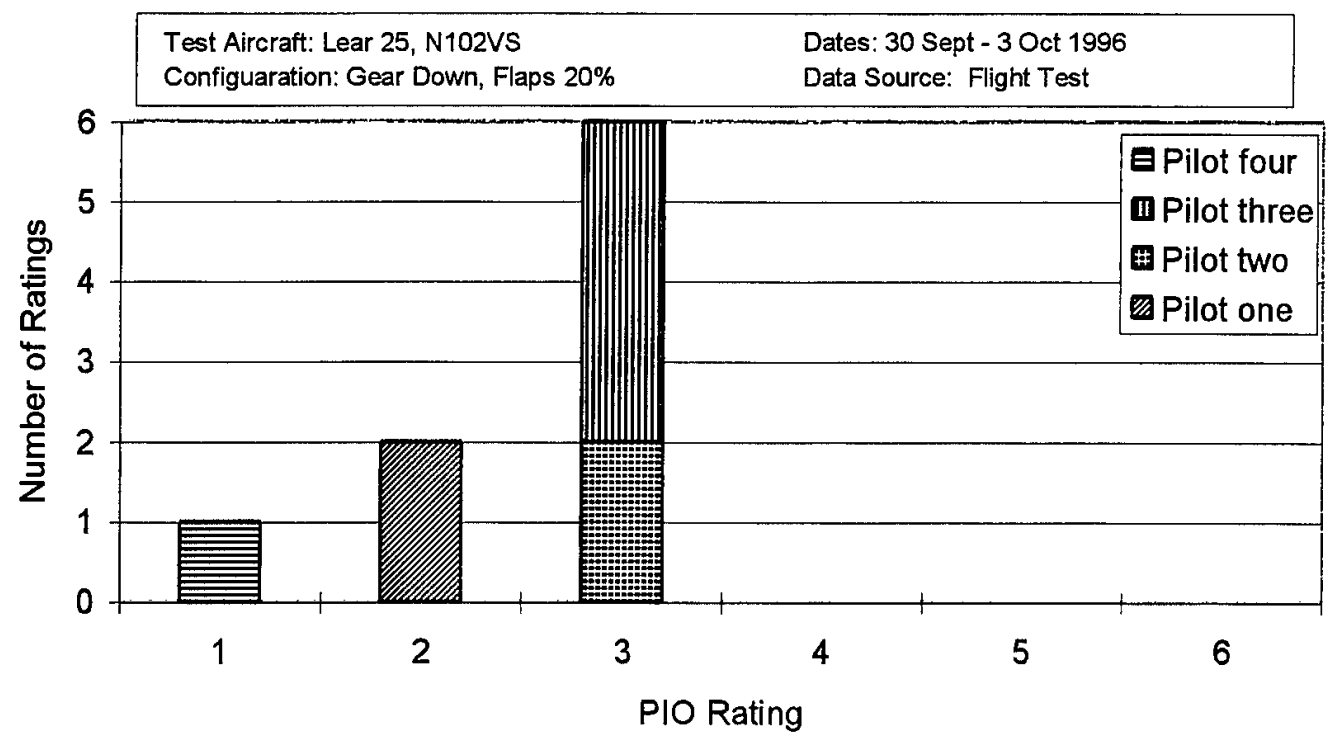

Figure $7 \mathrm{H}_{\infty}$ Flight Control Design Pilot Induced Oscillation Ratings 


\section{Mixed Noise Sensitivity and Output Energy Minimization Flight Control Configuration.}

The 4 evaluation pilots performed a total of 4 straight-in approaches and 10 offset landings with the mixed flight control design. See Figures 8 and 9 for $\mathrm{CH}$ and PIO ratings. The comments indicated that the aircraft felt sluggish and heavy on approach with a somewhat slow initial response. Two of the pilots indicated that the aircraft was somewhat unpredictable, while the other two considered the aircraft predictable. All four pilots stated that the aircraft handling qualities prior to the initiation of the flare were acceptable. For the 10 offset landings, 5 resulted in desired touchdown performance, 2 resulted in adequate, and 3 were inadequate. The flight control configuration had unacceptable behavior from flare initiation through landing rollout. All pilots commented on heave and float tendencies, and on at least four occasions, the aircraft became airborne after the initial touchdown. On every landing, all pilots required one-half to full forward stick to arrest an unanticipated pitchup motion after touchdown. Overall, the mixed flight control configuration was considered to have Level III handling qualities due to the unacceptable motions after flare through landing roll.

\section{Overall Results:}

The classical longitudinal flight control design exhibited Level II handling qualities for the approach and landing phase of flight. Pilot comments indicated that the three state-space designs exhibited acceptable handling qualities on final approach although no precise task was defined for this portion of the approach. All three state-space designs exhibited undesirable motion at some point between flare and the landing roll. This undesirable characteristic resulted in Level III ratings and the cause is not understood at this time. A further investigation into the cause of aircraft pitchup after landing for the three state-spaced flight control system designs should be conducted. (R2)

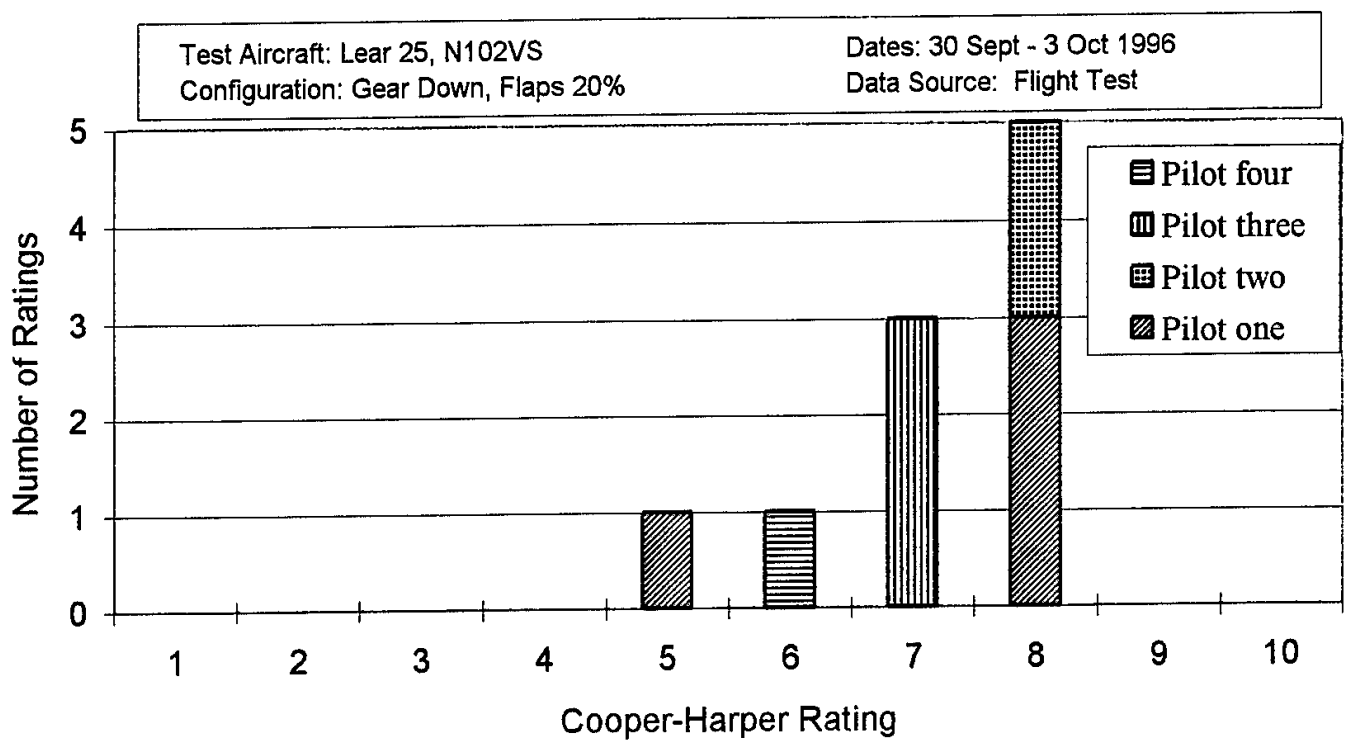

Figure 8 Mixed Flight Control Design Handling Quality Ratings 




Figure 9 Mixed Flight Control Design Pilot Induced Oscillation Ratings 
This page intentionally left blank. 


\section{CONCLUSIONS AND RECOMMENDATIONS}

Model validation analysis indicates that the noise sensitivity and output energy minimization $\mathrm{H}_{2}$ and $\mathrm{H}_{\infty}$ ) and mixed designs do not match the predicted response for these systems. Although the classical design model validation analysis tends to support that the intended aerodynamic model was adequately simulated by the Variable Stability Simulator II (VSS II) Learjet, the inconsistencies in the data for $\mathrm{H}_{2}, \mathrm{H}_{\infty}$, and mixed designs cast doubt on the accuracy of these design's implementation.

\section{Further analyses on the VSS II Learjet system and its limitations when implementing flight control system designs should be conducted to ensure proper configuration setup. (Page 6).}

The programmed test inputs (PTI) used did not contain sufficient low frequency content to analyze the system below 0.1 radians/second, where the predicted models contained some dynamics.

\section{Model validation testing should be conducted with frequency sweeps that provide a lower frequency content. (Page 5).}

The model validation inconsistencies cast doubt on the implementation and may impact accurate handling qualities ratings of these designs, but do not fully explain the undesirable characteristics exhibited on landing rollout. The designs, as implemented were evaluated for handling qualities.

The three longitudinal flight control systems designed using state-space optimization techniques were determined to have Level III handling qualities. The classically designed longitudinal flight control system was determined to have Level II handling qualities. Prior to the loss of pitch control authority in the flare after landing, pilot comments indicated acceptable handling qualities for the three state-space designs. The cause of the lightening of control forces in the flare and then the sudden pitchup after landing is not fully understood at this time and is beyond the scope of this report.

2. A further investigation into the cause of aircraft pitchup after landing for the three state-spaced flight control system designs should be conducted. (Page 10). 
This page intentionally left blank. 


\section{REFERENCES}

1. Doyle, John C., Bruce A. Francis, and Allen R. Tannenbaum, Feedback Control Theory, Macmillan Publishing Company, New York, New York, 1992.

2. Walker, D.E., $\mathrm{H}_{2}$ Optimal Control With $\mathrm{H}_{\infty}, \mu$, and $\mathrm{L}_{1}$ Constraints, Air Force Institute of Technology, AFIT/DS/AA/94-2, June 1994.

3. Doyle, John C., et al., State-Space Solutions to Standard $\mathrm{H}_{2}$ and $\mathrm{H}_{\infty}$ Control Problems, in IEEE Transactions on Automatic Control, Vol. 34, No. 8, August 1989, pp 831-847.

4. Walker, D.E. and D.B. Ridgely, Reduced Order Mixed $\mathrm{H}_{2} / \mathrm{H}_{\infty}$ Optimization With a Singular $\mathrm{H}_{\infty}$ Constraint, in Proceedings of the 1994 American Control Conference, Baltimore, MD, June 1994, pp 1,128-1,132.

5. Flying Qualities of Piloted Aircraft, MIL-STD-1797A, 30 January 1990.

6. USAF TPS Flying Qualities Phase Text Vol. IV, Flying Qualities Testing, USAF TPS/EDF, Edwards AFB, California, 1 June 1995.

7. Cooper, George E., and Robert P. Harper, The Use of Pilot Rating in the Evaluation of Aircraft Handling Qualities, NASA Technical Note D-5153, National Aeronautics and Space Administration, Washington, D.C., April 1969.

8. Smith, Ralph H., and Norman D. Geddes, Handling Qualities Requirements for Advanced Aircraft Design: Longitudinal Mode, AFFDL-TR-86-44, AFFDL, Wright-Patterson AFB, Ohio, August 1979. 
This page intentionally left blank. 


\section{BIBLIOGRAPHY}

Memorandum for Record. Preliminary Safety Approval for HAVE INFINITY and HAVE GRIP Flight Training and Ground Test, USAF Test Pilot School, Edwards AFB, California, 4 September 1996.

Safety Review Package, Control number 96-91. HAVE INFINITY, USAF Test Pilot School, Edwards AFB, California, September 1996.

U.S. Air Force/U.S. Navy Test Pilot School Variable Stability Programs. Learjet Flight Syllabus and Background Material, ed. Buethe, Scott, February 1994. 
This page intentionally left blank. 
APPENDIX A

LEARJET DETAILS 
This page intentionally left blank. 


\section{LEARJET DETAILS}

The Learjet Model 25 has been highly modified to serve as a three axis in-flight simulator for use as a teaching aid at the USAF and USN Test Pilot Schools. It is operated by CALSPAN under an experimental license from the FAA.

The variable stability controls are installed in the right seat. The system can be disengaged by any of four manual disconnect switches which are installed on each of the three control sticks/yokes and on the glare shield. In addition, automatic safety trips are provided. In the event of incapacitation of the safety pilot or certain control cable failures, the aircraft can be flown by the evaluation pilot as a nearly normal Learjet using the Variable Stability Simulator (VSS) in the "Fly-by-Wire" (FBW) mode. All basic Learjet systems are available in the FBW mode except for nosegear steering. The handling qualities are those of the basic aircraft with the yaw damper on. There are no safety trips in the emergency FBW mode.

Hydraulic power for the variable stability actuators was obtained from the existing Learjet hydraulic system which provides 4 gallons per minute (gpm) per engine. Estimated maximum flow demand to operate all servo actuators is $3.35 \mathrm{gpm}$. Maximum demand for normal Learjet flaps, spoilers, gear, and brakes were under $4 \mathrm{gpm}$. Solenoid operated valves to the variable stability actuators are designed fail safe to prevent hydraulic locks on the actuators.

Operating limitations that apply to the Learjet are listed in Table A1.

Table A1

LEARJET LIMITATIONS

\begin{tabular}{|c|c|c|}
\hline & VSS Off & VSS On \\
\hline Speed Limitations & 356 KIAS/0.82 Mach & 325 KIAS \\
\hline g Limitations & +4.4 to -1.0 & +2.8 to +0.15 \\
\hline
\end{tabular}

Note: VSS - variable stability simulator 
This page intentionally left blank. 


\section{APPENDIX B}

TEST CARDS, COOPER-HARPER RATING SCALE, AND PILOT INDUCED OSCILLATION RATING SCALE 
This page intentionally left blank. 


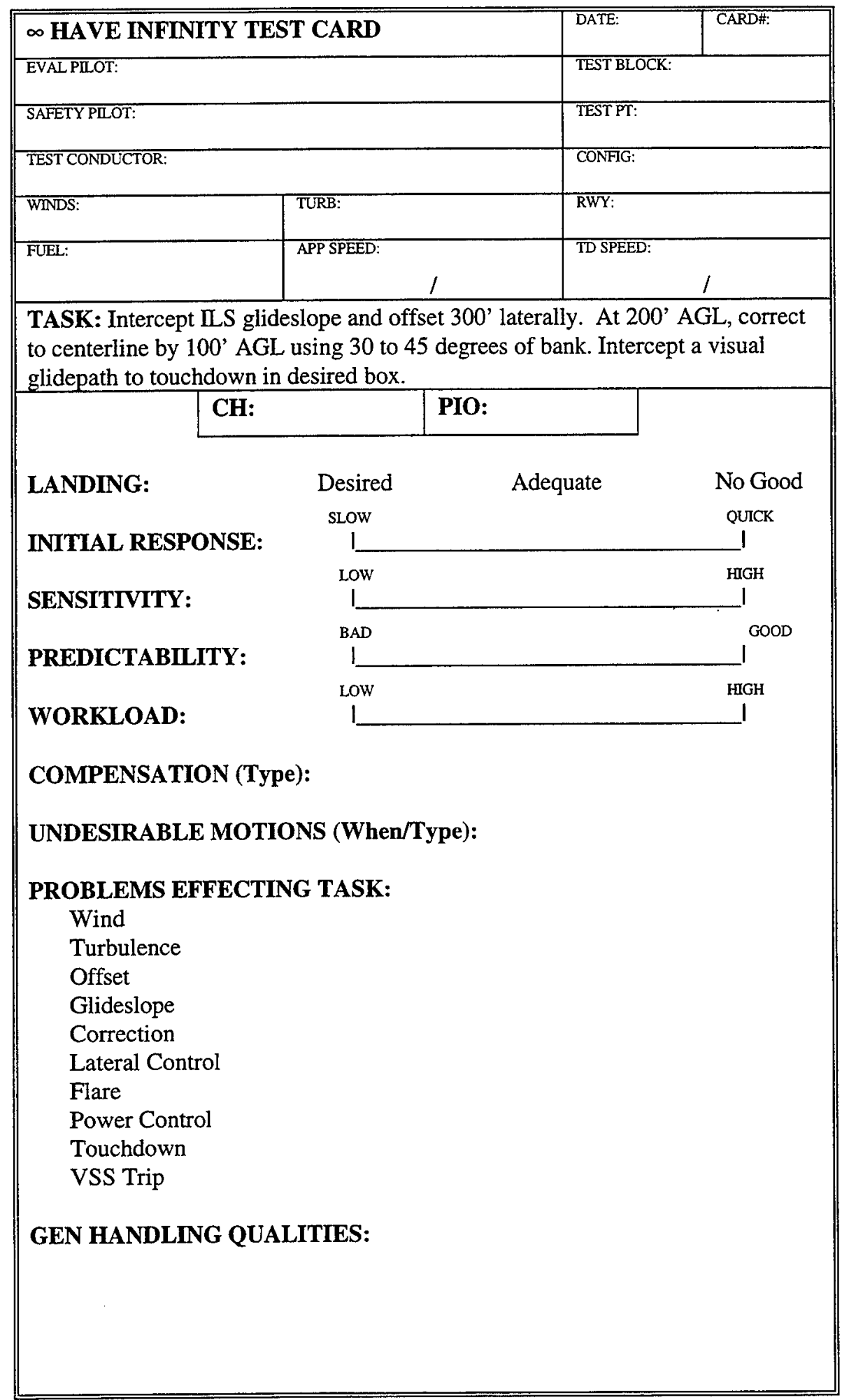

Figure B1 Sample Test Card 


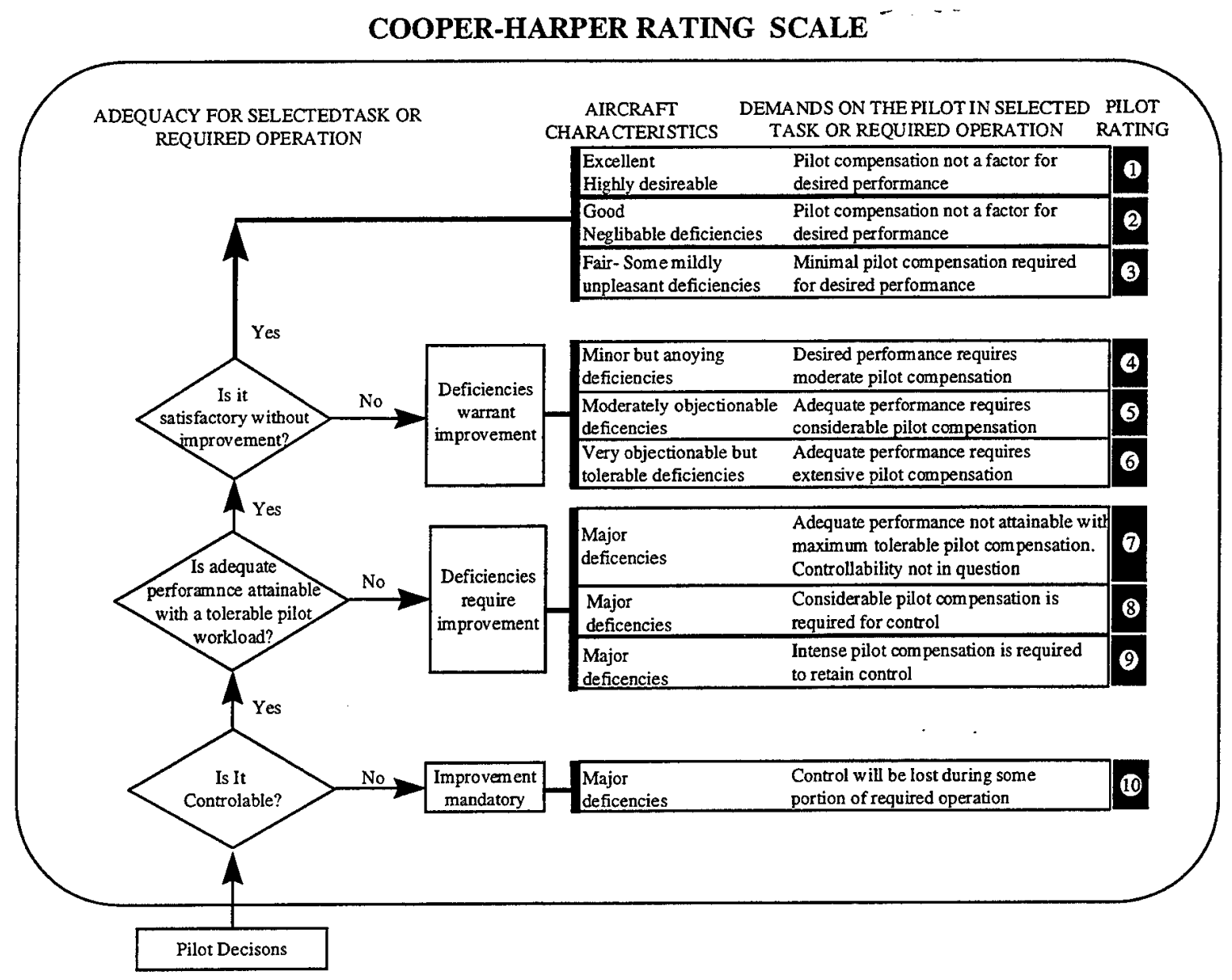

Figure B2 Cooper-Harper Rating Scale 




Notes: 1. PIO 1 - No tendency for pilot to induce undesirable motion.

2. $\underline{\text { PIO 2 }}$ - Undesirable motion tends to occur when pilot initiates abrupt maneuvers or attempts tight control. These motions can be prevented or eliminated by pilot technique.

3. PIO 3 - Undesirable motions easily induced when pilot initiates abrupt maneuvers or attempts tight control. These motions can be prevented or eliminated, but only at sacrifice to task performance or through considerable pilot attention and effort.

4. PIO 4 - Oscillations tend to develop when pilot initiates abrupt maneuvers or attempts tight control. Pilot must reduce gain or abandon task to recover.

5. PIO 5 - Divergent oscillations tend to develop when pilot initiates abrupt maneuvers or attempts tight control. Pilot must reduce gain or abandon task to recover.

6. PIO 6 - Disturbance or normal control may cause divergent oscillation. Pilot must open control loop by releasing or freezing the stick.

Figure B3 PIO Rating Scale Decision Tree 
This page intentionally left blank. 
APPENDIX C

PILOT COMMENTS DATABASE 
This page intentionally left blank 


\section{CONFIGURATION ID Classical}

\begin{tabular}{lll}
\hline Mission date: & 30 Sep 96 & Eval pilot: Fittante
\end{tabular}

Handling qualities: The aircraft was responsive and predictable. Overall the pilot stated that this configuration had nice handling qualities.

Landing: The nose tracked well and the task was easy to perform.

$\begin{array}{llllll}\text { Appr } & \text { Landing zone } & \text { Turb } & \text { Wind } & \text { C-H Rating } & \text { PIO Rating } \\ 1 & \text { Desired } & \text { none } & \text { calm } & 3 & 1 \\ 2 & \text { Desired } & \text { none } & \text { calm } & 3 & 1 \\ 3 & \text { Desired } & \text { none } & \text { calm } & 3 & 1\end{array}$

Notes on C-H: All four had desired performance and minimal workload.

Notes on PIO Rating: No undesirable motions were noted.

\begin{tabular}{lll}
\hline Mission date: 1 Oct 96 & Eval pilot: Edwards & Flight \#
\end{tabular}

Handling qualities: The aircraft had a quick response and was fairly predictable with moderate to high sensitivity.

Landing: There was no tendency to balloon or bounce with this configuration.

$\begin{array}{llllll}\text { Appr } & \text { Landing zone } & \text { Turb } & \text { Wind } & \text { C-H Rating } & \text { PIO Rating } \\ 1 & \text { Desired } & \text { Light } & \text { vrb/4 } & 4 & 2 \\ 2 & \text { Desired } & \text { Light } & \text { vrb/4 } & 4 & 1\end{array}$

Notes on C-H: Moderate workload was required because the response of this configuration required the pilot to make quick, abrupt inputs to maintain glide path.

Notes on PIO Rating: There was a tendency to over flare for the first approach and no unwanted motions were perceived on the second approach.

Mission date: 2 Oct 96

Eval pilot: Malacrida

Flight \# 3

Handling qualities: The aircraft predictability was good and the sensitivity was nice. The stick was a bit heavy.

Landing: No problems noted on landing.

$\begin{array}{llllll}\text { Appr } & \text { Landing zone } & \text { Turb } & \text { Wind } & \text { C-H Rating } & \text { PIO Rating } \\ 1 & \text { Desired } & \text { none } & 180 / 3 & 4 & 2 \\ 2 & \text { Desired } & \text { none } & 180 / 3 & 4 & 2\end{array}$

Notes on C-H: The pilot described his workload as moderate, but also commented that this is a borderline level one design.

Notes on PIO Rating: A slight bobble resulted during the ILS glideslope capture and resulted in a PIO 2. 


\section{CONFIGURATION ID Classical}

\begin{tabular}{lll}
\hline Mission date: 2 Oct 96 & Eval pilot: Fittante & Flight \# 4
\end{tabular}

Handling qualities: The aircraft had good response with fairly light stick forces.

Landing: The aircraft nose stayed down after landing.

$\begin{array}{llllll}\text { Appr } & \text { Landing zone } & \text { Turb } & \text { Wind } & \text { C-H Rating } & \text { PIO Rating } \\ 1 & \text { Desired } & \text { none } & \text { vrb/5 } & 3 & 1\end{array}$

Notes on C-H: Minimal workload was required.

Notes on PIO Rating: No unwanted motions were observed.

Mission date: 3 Oct $96 \quad$ Eval pilot: Bouchard

Flight \# 5

Handling qualities: The aircraft had moderate to slow initial response, with moderate sensitivity, predictability and workload.

Landing: The pilot felt he flared a little to high which resulted in a firm landing for the first approach and the aircraft had excessive aft stick required for flare.

$\begin{array}{lllll}\text { Appr } & \text { Landing zone } & \text { Turb } & \text { Wind } & \text { C-H Rating } \\ 1 & \text { Adequate } & \text { none } & 220 / 6 & 5 \\ 2 & \text { Desired } & \text { none } & 220 / 6 & 4\end{array}$

Notes on C-H: A CH 5 was given for the first approach because of adequate performance, but the pilot commented that the handling qualities were more representative of $\mathrm{CH} 3$. The second approach was given a $\mathrm{CH} 4$ because of moderate compensation in the form of excessive aft stick required to flare. 
CONFIGURATION ID $\mathbf{H}_{2}$

Mission date: $30 \operatorname{Sep} 96 \quad$ Eval pilot: Fittante $\quad$ Flight \# 1

Handling qualities: The aircraft had heavy stick forces and didn't want to move. It was very stable with a dead beat response, and was unresponsive. Sharp inputs caused a slight pitch bobble.

Landing: The aircraft was not evaluated for control after touchdown since the evaluation pilot tripped off the VSS.

$\begin{array}{llllll}\text { Appr } & \text { Landing zone } & \text { Turb } & \text { Wind } & \text { C-H Rating } & \text { PIO Rating } \\ 1 & \text { Desired } & \text { none } & \text { calm } & 4 & 2 \\ 2 & \text { Desired } & \text { none } & \text { calm } & 4 & 2 \\ 3 & \text { Desired } & \text { none } & \text { calm } & 4 & 2\end{array}$

Notes on C-H: On the second approach the initial correction was input with the aircraft one dot above glideslope causing a third approach.

Notes on PIO Rating: The rating of 2 was given due to the slight pitch bobble.

Mission date: 1 Oct 96

Eval pilot: Edwards

Flight \# 2

Handling qualities: The aircraft was very quick in response, jittery, and required low gain smooth inputs to obtain the desired results.

Landing: During the flare the stick had to be rapidly brought forward to lower the nose.

$\begin{array}{llllll}\text { Appr } & \text { Landing zone } & \text { Turb } & \text { Wind } & \text { C-H Rating } & \text { PIO Rating } \\ 1 & \text { Desired } & \text { Light } & 160 / 3 & 5 & 3 \\ 2 & \text { Desired } & \text { Light } & 230 / 6 & 4 & 1\end{array}$

Notes on C-H: Sensitivity to control inputs made the aircraft unpredictable which increased workload for the first approach. For the second approach workload decreased due to a learning curve.

Notes on PIO Rating: Undesirable motions caused the rating of 3 for the first approach, but were not perceived on the second approach which was given a rating of 1. 
CONFIGURATION ID $\mathrm{H}_{2}$

Mission date: 2 Oct 96

Eval pilot: Malacrida

Flight \# 3

Handling qualities: The aircraft had poor pitch predictability for higher gain inputs. The initial response of the aircraft was slow and sensitivity was low.

Landing: The pilot needed small pulse inputs to flare. The aircraft was barely controllable on the ground requiring high pilot compensation.

$\begin{array}{llllll}\text { Appr } & \text { Landing zone } & \text { Turb } & \text { Wind } & \text { C-H Rating } & \text { PIO Rating } \\ 1 & \text { Desired } & \text { none } & 280 / 6 & 8 & 4 \\ 2 & \text { Desired } & \text { none } & 280 / 6 & 8 & 4\end{array}$

Notes on C-H: The pilot had full forward stick applied at touchdown and still had difficulty keeping the aircraft on the ground.

Notes on PIO Rating: Significant non oscillatory, undesirable motions were seen on the ground.

Mission date: 2 Oct 96

Eval pilot: Fittante

Flight \# 4

Handling qualities: The aircraft had heavy stick forces and was sluggish. The heavier forces and delayed response produced a little oscillation on final.

Landing: At approximately two seconds after touchdown full forward stick was required to keep the nose from pitching up.

$\begin{array}{llllll}\text { Appr } & \text { Landing zone } & \text { Turb } & \text { Wind } & \text { C-H Rating } & \text { PIO Rating } \\ 1 & \text { Desired } & \text { none } & \text { vrb/5 } & 6 & 3 \\ 2 & \text { Desired } & \text { none } & \text { vrb/5 } & 8 & 3\end{array}$

Notes on C-H: Compensation was mainly required for the sluggish pitch response and the pitch up after landing. On the second approach controllability was in question after touchdown.

Notes on PIO Rating: The rating of 3 was given for the undesired motion on final.

\begin{tabular}{lll}
\hline Mission date: 3 Oct 96 & Eval pilot: Bouchard & Flight 5
\end{tabular}

Handling qualities: The aircraft had low sensitivity, bad predictability and high workload. On final approach the aircraft seemed to handle fine.

Landing: On the straight-in at touchdown the aircraft bounced and began an uncontrollable pitch up maneuver upon which the safety pilot disengaged the VSS II and initiated a go around.

Notes on C-H: Although this test did not consider the straight-in an operational task with regards to CooperHarper ratings, the configuration was deemed uncontrollable. 


\section{CONFIGURATION ID $\mathbf{H}_{2}$}

\begin{tabular}{lll}
\hline Mission date: 3 Oct 96 & Eval pilot: Malacrida & Flight \# 6
\end{tabular}

Handling qualities: The initial response of the aircraft was good but the sensitivity was low to moderate and the predictability was bad.

Landing: At approximately two seconds after touchdown full forward stick was required to keep the nose from pitching up.

$\begin{array}{llllll}\text { Appr } & \text { Landing zone } & \text { Turb } & \text { Wind } & \text { C-H Rating } & \text { PIO Rating } \\ 1 & \text { Not adequate } & \text { none } & \text { vrb/5 } & 7 & 4\end{array}$

Notes on C-H: The $\mathrm{CH} 7$ was based on the long landing and the problems in the flare.

Notes on PIO Rating: The task was abandon due to pitch bobble and uncommanded pitchup.

\begin{tabular}{lll}
\hline Mission date: 3 Oct 96 & Eval pilot: Bouchard & Flight \# 6
\end{tabular}

Handling qualities: The aircraft had good initial response with slightly low sensitivity and bad predictability.

Landing: Forward stick required in flare and landing to keep the aircraft from ballooning.

$\begin{array}{llllll}\text { Appr } & \text { Landing zone } & \text { Turb } & \text { Wind } & \text { C-H Rating } & \text { PIO Rating } \\ 1 & \text { Desired } & \text { none } & \text { vrb/5 } & 10 & 1 \\ 2 & \text { Desired } & \text { none } & \text { vrb/5 } & 9 & 1\end{array}$

Notes on C-H: The aircraft was uncontrollable after touchdown for the first approach and with full stick on the second approach the aircraft marginal control on rollout. 


\section{CONFIGURATION ID $\mathbf{H}_{\infty}$}

\begin{tabular}{lll}
\hline Mission date: 1 Oct 96 & Eval pilot: Edwards & Flight \# 2
\end{tabular}

Handling qualities: The stick inputs were sensitive with a quick initial response, glidepath was not difficult to maintain

Landing: The aircraft wanted to float in the flare. During the flare the stick had to be brought forward to prevent ballooning.

$\begin{array}{llllll}\text { Appr } & \text { Landing zone } & \text { Turb } & \text { Wind } & \text { C-H Rating } & \text { PIO Rating } \\ 1 & \text { Safety trip } & \text { Light } & 190 / 5 & 7 & 2 \\ 2 & \text { Adequate } & \text { Light } & 190 / 5 & 7 & 2\end{array}$

Notes on C-H: On the first rated approach the safety pilot took control prior to touchdown due to a high sink rate. On the second approach touched down in the adequate box with the aircraft ballooning.

Notes on PIO Rating: A PIO of 2 was given due to unwanted motion in the flare.

Mission date: 2 Oct $96 \quad$ Eval pilot: Malacrida $\quad$ Flight \# 3

Handling qualities: The aircraft was predictable and had good pitch response until the pilot gains were increased.

Landing: The aircraft had a tendency to float on the runway. Too much forward stick was required during the flare.

$\begin{array}{llllll}\text { Appr } & \text { Landing zone } & \text { Turb } & \text { Wind } & \text { C-H Rating } & \text { PIO Rating } \\ 1 & \text { Not Adequate } & \text { none } & 280 / 6 & 7 & 3 \\ 2 & \text { Adequate } & \text { none } & 280 / 6 & 5 & 3 \\ 3 & \text { Not Adequate } & \text { none } & 280 / 6 & 7 & 3\end{array}$

Notes on C-H: Workload was not an issue, poor performance drove the $\mathrm{CH} 5$ and 7's.

Notes on PIO Rating: The unwanted motion of the heave and float at flare resulted in a PIO 3. 


\section{CONFIGURATION ID $\mathrm{H}_{\infty}$}

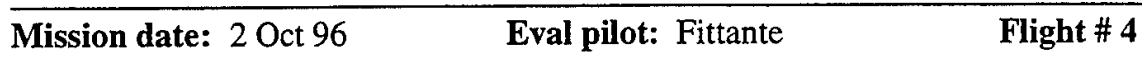

Handling qualities: The aircraft had good aircraft response through the correction to centerline with light pitch forces.

Landing: The aircraft wanted to float and forward stick was required for touchdown. Full forward stick was required to keep the nose on the runway.

$\begin{array}{llllll}\text { Appr } & \text { Landing zone } & \text { Turb } & \text { Wind } & \text { C-H Rating } & \text { PIO Rating } \\ 1 & \text { Desired } & \text { none } & \text { vrb/5 } & 8 & 3 \\ 2 & \text { Desired } & \text { none } & \text { vrb/5 } & 8 & 3\end{array}$

Notes on C-H: The aircraft was just barely controllable for both landings after touchdown.

Notes on PIO Rating: A PIO rating of 3 was assigned for the easily induced jittery aircraft response during the flare as stick forces became lighter.

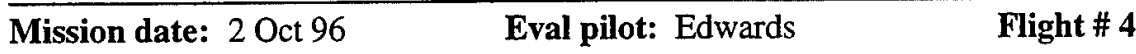

Handling qualities: The lateral correction was easily accomplished with heavy stick forces.

Landing: The aircraft had a tendency to balloon in the flare and full forward stick was required to keep the aircraft on the ground.

$\begin{array}{llllll}\text { Appr } & \text { Landing zone } & \text { Turb } & \text { Wind } & \text { C-H Rating } & \text { PIO Rating } \\ 1 & \text { Desired } & \text { none } & 200 / 5 & 8 & 2 \\ 2 & \text { Desired } & \text { none } & 200 / 5 & 7 & 2\end{array}$

Notes on C-H: Pilot workload to prevent the aircraft from pitching up drove the $\mathrm{CH}$ ratings.

Notes on PIO Rating: A PIO of 2 was given due to unwanted motion during and after touchdown.

Mission date: 3 Oct 96

Eval pilot: Bouchard

Flight \# 5

Handling qualities: The aircraft had moderate to quick initial response, with moderate to highly sensitive, slightly unpredictable and moderate workload.

Landing: Forward stick was required to keep the nose down.

$\begin{array}{lllll}\text { Appr } & \text { Landing zone } & \text { Turb } & \text { Wind } & \text { C-H Rating } \\ 1 & \text { Desired } & \text { none } & 220 / 6 & 7 \\ 2 & \text { Desired } & \text { none } & 220 / 6 & 9\end{array}$

Notes on C-H: The design was considered level 3 because of the roll out characteristics. The first received a $\mathrm{CH} 7$ because of extensive pilot compensation without questionable controllability. The second received a $\mathrm{CH} 9$ because controllability was in question after touchdown. 
CONFIGURATION ID $\mathrm{H}_{\infty}$

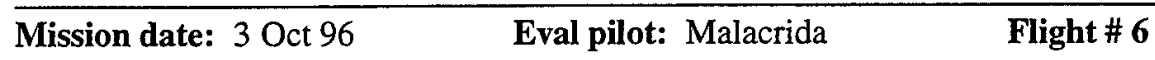

Handling qualities: The aircraft had adequate initial response and sensitivity but it had bad predictability.

Landing: A forward stick was required at flare to keep the aircraft from ballooning.

$\begin{array}{llllll}\text { Appr } & \text { Landing zone } & \text { Turb } & \text { Wind } & \text { C-H Rating } & \text { PIO Rating } \\ 1 & \text { Not adequate } & \text { none } & \operatorname{vrb} / 5 & 7 & 3\end{array}$

Notes on C-H: The aircraft landed long.

Notes on PIO Rating: The rating of 3 was given for the undesired motion on final.

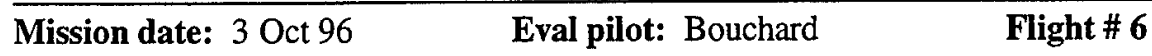

Handling qualities: The aircraft had adequate initial response with low sensitivity and bad predictability.

Landing: After touchdown forward stick was required to keep the nose from pitching up:

$\begin{array}{llllll}\text { Appr } & \text { Landing zone } & \text { Turb } & \text { Wind } & \text { C-H Rating } & \text { PIO Rating } \\ 1 & \text { Adequate } & \text { none } & \text { vrb/5 } & 6 & 1\end{array}$

Notes on C-H: The aircraft landed in the adequate zone with high workload. 
CONFIgURATION ID Mixed $\mathrm{H}_{2} / \mathrm{H}_{\infty}$

Mission date: 1 Oct $96 \quad$ Eval pilot: Edwards $\quad$ Flight \# 2

Handling qualities: The aircraft handled well coming down final and during the offset task. The aircraft initial response seemed slow.

Landing: During the flare the stick had to be brought forward to prevent ballooning.

$\begin{array}{llllll}\text { Appr } & \text { Landing zone } & \text { Turb } & \text { Wind } & \text { C-H Rating } & \text { PIO Rating } \\ 1 & \text { Desired } & \text { none } & 230 / 6 & 5 & 2 \\ 2 & \text { Desired } & \text { none } & 230 / 6 & 8 & 2\end{array}$

Notes on C-H: On the first approach a $\mathrm{CH} 5$ was given due to high workload. On the second approach a $\mathrm{CH} 8$ was given due to unpredictable aircraft motion after touchdown

Notes on PIO Rating: A PIO of 2 was given due to unwanted motion after touchdown.

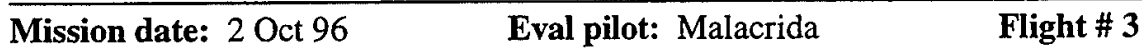

Handling qualities: The aircraft felt heavy with a sluggish response and was not terribly predictable.

Landing: The aircraft exhibited a heave with the flare.

$\begin{array}{llllll}\text { Appr } & \text { Landing zone } & \text { Turb } & \text { Wind } & \text { C-H Rating } & \text { PIO Rating } \\ 1 & \text { Adequate } & \text { none } & 280 / 6 & 7 & 3 \\ 2 & \text { Not adequate } & \text { none } & 280 / 6 & 7 & 3\end{array}$

Notes on C-H: The pilot gave $\mathrm{CH} 7$ because of the high workload and extensive compensation. The pilot had to consciously lower his gains and apply his inputs early.

Notes on PIO Rating: The unwanted motion of the heave at flare resulted in a PIO 3.

Mission date: 2 Oct 96

Eval pilot: Fittante

Flight \# 4

Handling qualities: The aircraft had slightly high stick forces and pitch control was solid during transition to landing until just prior to touchdown.

Landing: At touchdown there was a sudden reversal in pitch force, requiring full forward stick to keep the nose on the runway.

$\begin{array}{llllll}\text { Appr } & \text { Landing zone } & \text { Turb } & \text { Wind } & \text { C-H Rating } & \text { PIO Rating } \\ 1 & \text { Desired } & \text { none } & \text { vrb/5 } & 8 & 1 \\ 2 & \text { Desired } & \text { none } & \text { vrb/5 } & 8 & 1\end{array}$

Notes on C-H: $\mathrm{CH} 8$ was given for controllability during and after touchdown.

Notes on PIO Rating: The PIO rating of 1 was given because there was no longer a jittery response during the transition to landing. 


\section{CONFIGURATION ID Mixed $\mathrm{H}_{2} / \mathrm{H}_{\infty}$}

\begin{tabular}{lll}
\hline Mission date: 2 Oct 96 & Eval pilot: Edwards & Flight \# 4
\end{tabular}

Handling qualities: The initial response was good with adequate sensitivity and bad predictability.

Landing: Full forward stick was applied after touchdown, but the aircraft became airborne again after both landings.

$\begin{array}{llllll}\text { Appr } & \text { Landing zone } & \text { Turb } & \text { Wind } & \text { C-H Rating } & \text { PIO Rating } \\ 1 & \text { Desired } & \text { none } & \text { vrb/5 } & 8 & 2 \\ 2 & \text { Desired } & \text { none } & \operatorname{vrb} / 5 & 8 & 2\end{array}$

Notes on C-H: Considerable pilot compensation was required.

Notes on PIO Rating: A PIO of 2 was given due to unwanted motion after touchdown.

Mission date: 3 Oct 96

Eval pilot: Bouchard

Flight \# 5

Handling qualities: The aircraft had moderate initial response, with low to moderate sensitivity, bad predictability and high workload.

Landing: At touchdown, during the straight-in, the aircraft bounced and began an uncontrollable pitchup maneuver similar to configuration L. At this time the pilot requested the safety pilot to take control of the aircraft.

Notes on C-H: Although this test did not consider the straight-in an operational task with regards to CooperHarper ratings, the configuration was deemed uncontrollable.

Mission date: 3 Oct 96

Eval pilot: Malacrida

Flight \# 6

Handling qualities: The aircraft had adequate initial response but moderately low sensitivity and bad predictability.

Landing: After touchdown forward stick was required to keep the nose from pitching up.

$\begin{array}{llllll}\text { Appr } & \text { Landing zone } & \text { Turb } & \text { Wind } & \text { C-H Rating } & \text { PIO Rating } \\ 1 & \text { Not adequate } & \text { none } & \text { vrb/5 } & 7 & 3\end{array}$

Notes on C-H: The aircraft landed long.

Notes on PIO Rating: The rating of 3 was given for the undesired motion on final. 


\section{CONFIGURATION ID Mixed $\mathrm{H}_{2} / \mathrm{H}_{\infty}$}

Mission date: 3 Oct $96 \quad$ Eval pilot: Bouchard $\quad$ Flight \# 6

Handling qualities: The aircraft had adequate initial response and sensitivity and bad predictability.

Landing: After touchdown full forward stick was required to keep the nose from pitching up.

$\begin{array}{llllll}\text { Appr } & \text { Landing zone } & \text { Turb } & \text { Wind } & \text { C-H Rating } & \text { PIO Rating } \\ 1 & \text { Adequate } & \text { none } & \text { vrb/5 } & 6 & 1\end{array}$

Notes on C-H: Landed in the adequate zone and had high workload. 
This page intentionally left blank. 


\section{APPENDIX D}

\section{RECORDED PARAMETERS}


This page intentionally left blank. 
Table D1

Data Acquisition Parameters Recorded During Testing

\begin{tabular}{|c|c|c|c|}
\hline Parameter & Units & Parameter & Units \\
\hline HOURS & & alpha_c & deg \\
\hline MINUTES & & alphadot & $\mathrm{deg} / \mathrm{s}$ \\
\hline SECONDS & & beta_cf & $\operatorname{deg}$ \\
\hline MSECONDS & & beta_c & deg \\
\hline engaged & & $\mathrm{hp}$ & $\mathrm{ft}$ \\
\hline fes & $\mathrm{lb}$ & h_dot & $\mathrm{ft} / \mathrm{sec}$ \\
\hline fas & $\mathrm{lb}$ & 1_thrust & $\mathrm{lb}$ \\
\hline frp & $\mathrm{lb}$ & r_thrust & $\mathrm{lb}$ \\
\hline des & in & fuel_tot & $\mathrm{lb}$ \\
\hline das & $\mathrm{deg}$ & fuel_fus & $\mathrm{lb}$ \\
\hline $\mathrm{drp}$ & in & oat & $\operatorname{deg} \mathrm{K}$ \\
\hline $\mathrm{dec}$ & deg & pti & deg \\
\hline dac & $\mathrm{deg}$ & des_in & inch \\
\hline $\mathrm{drc}$ & deg & de_virt & deg \\
\hline $\mathrm{de}$ & $\mathrm{deg}$ & dec_fb & deg \\
\hline ds & deg & de_test & $\mathrm{deg}$ \\
\hline $\mathrm{da}$ & $\mathrm{deg}$ & de_augm & deg \\
\hline $\mathrm{dr}$ & deg & de_virt 2 & deg \\
\hline theta & deg & dec_m $m$ & $\mathrm{deg}$ \\
\hline phi & deg & dec_lj & deg \\
\hline psi & deg & alpha_in & deg \\
\hline$p$ & $\mathrm{deg} / \mathrm{sec}$ & $\mathrm{q}_{\text {_in }}$ & $\mathrm{deg} / \mathrm{s}$ \\
\hline $\mathrm{q}$ & $\mathrm{deg} / \mathrm{sec}$ & kout & deg \\
\hline $\mathrm{r}$ & $\mathrm{deg} / \mathrm{sec}$ & $\mathrm{x} 1$ & deg \\
\hline $\mathrm{nx}$ & $\mathrm{G}$ & $\mathrm{x} 2$ & deg \\
\hline ny & $\mathrm{G}$ & $\mathrm{x} 3$ & deg \\
\hline $\mathrm{nz}$ & $\mathrm{G}$ & $\mathrm{x} 4$ & $\operatorname{deg}$ \\
\hline nzp & $\mathrm{G}$ & $\mathrm{x} 5$ & $\mathrm{deg}$ \\
\hline vi & knots & $\mathrm{x} 6$ & deg \\
\hline ve & knots & f16_a & $\mathrm{deg} / \mathrm{sec}$ \\
\hline $\mathrm{vt}$ & $\mathrm{ft} / \mathrm{sec}$ & f16_alpha & deg \\
\hline alpha_cf & deg & fcs_confignond & $1-4$ \\
\hline
\end{tabular}


This page intentionally left blank. 
APPENDIX E

DATA ANALYSIS PLOTS 
This page intentionally left blank. 


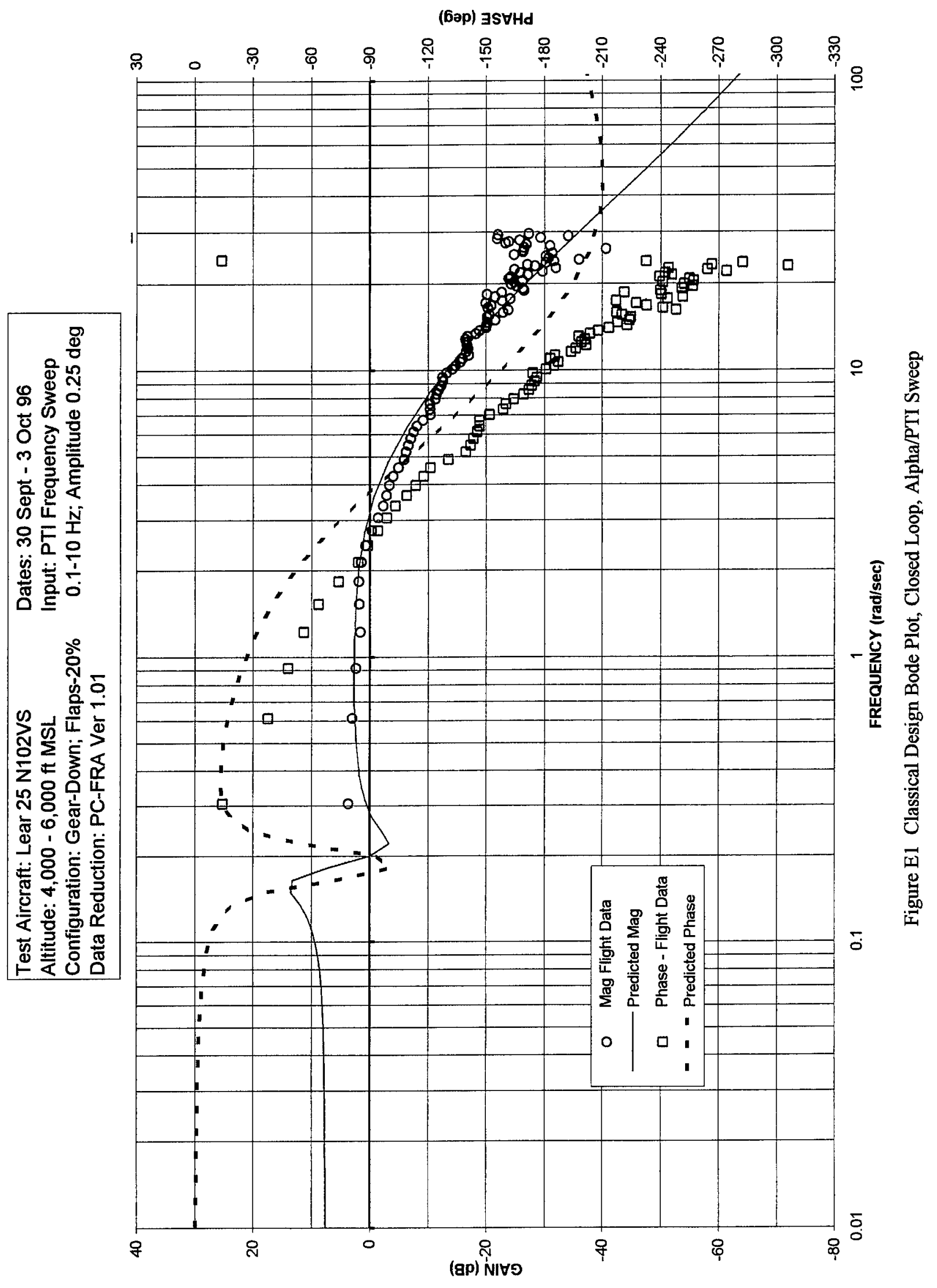









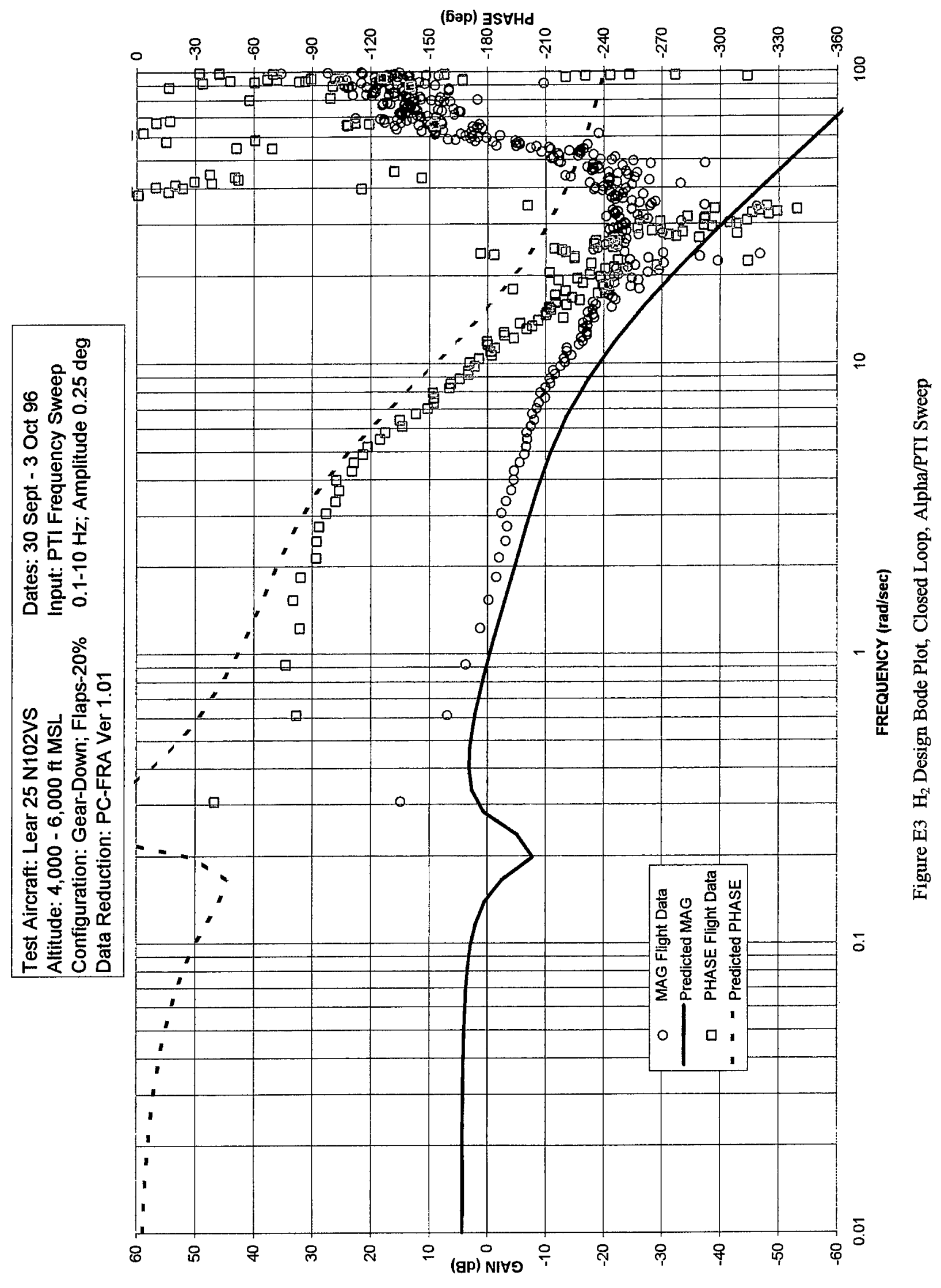









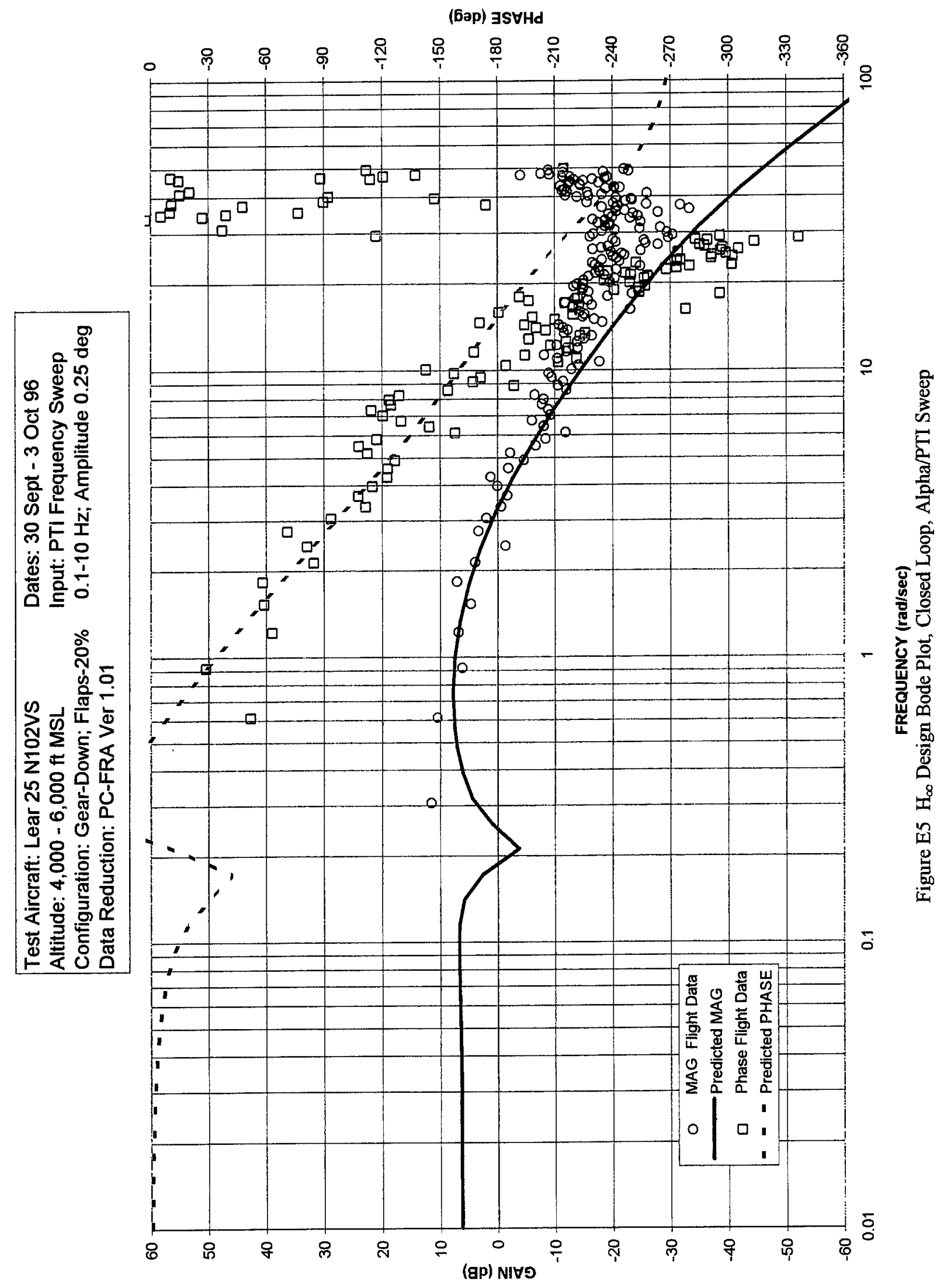




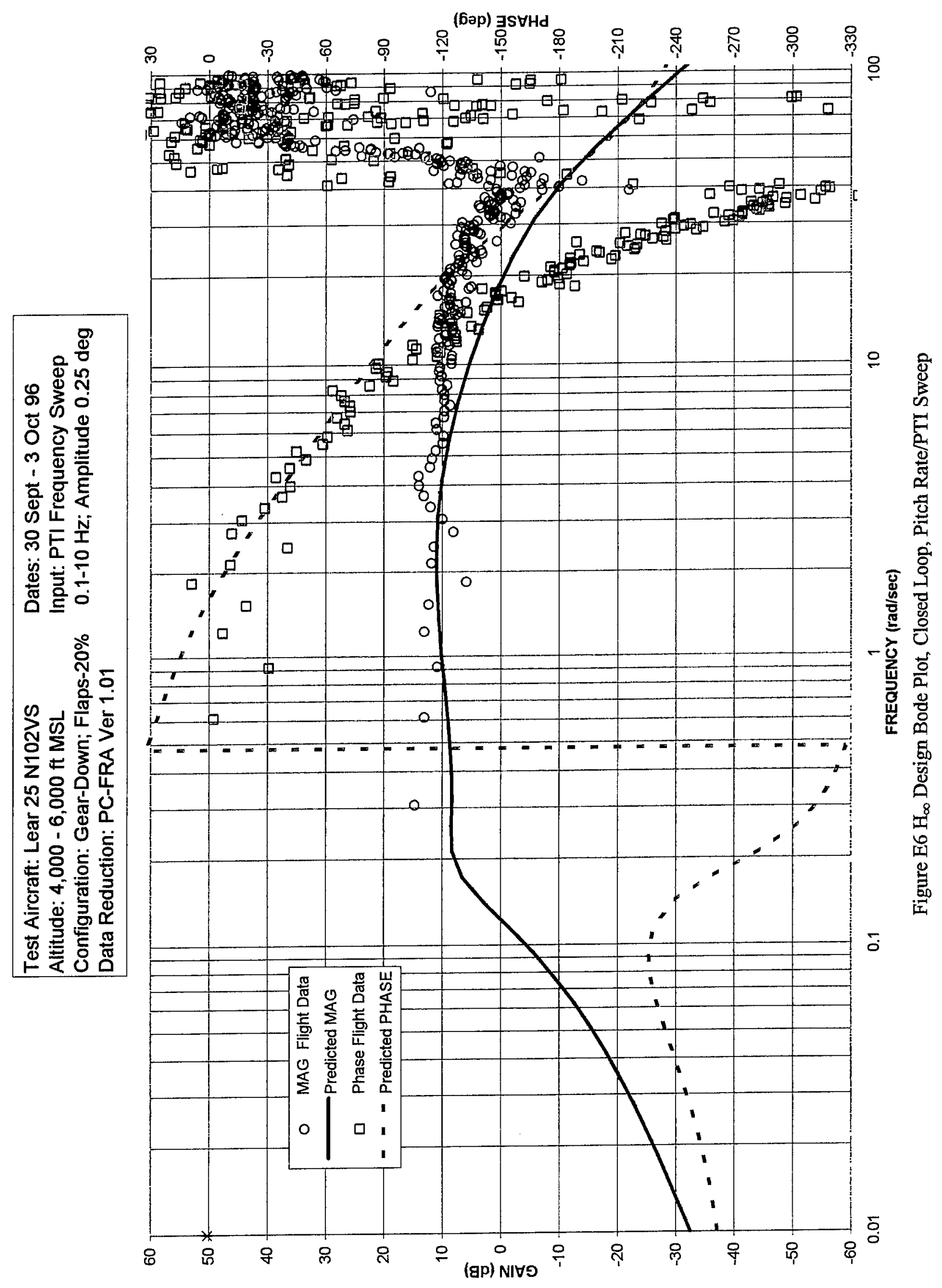




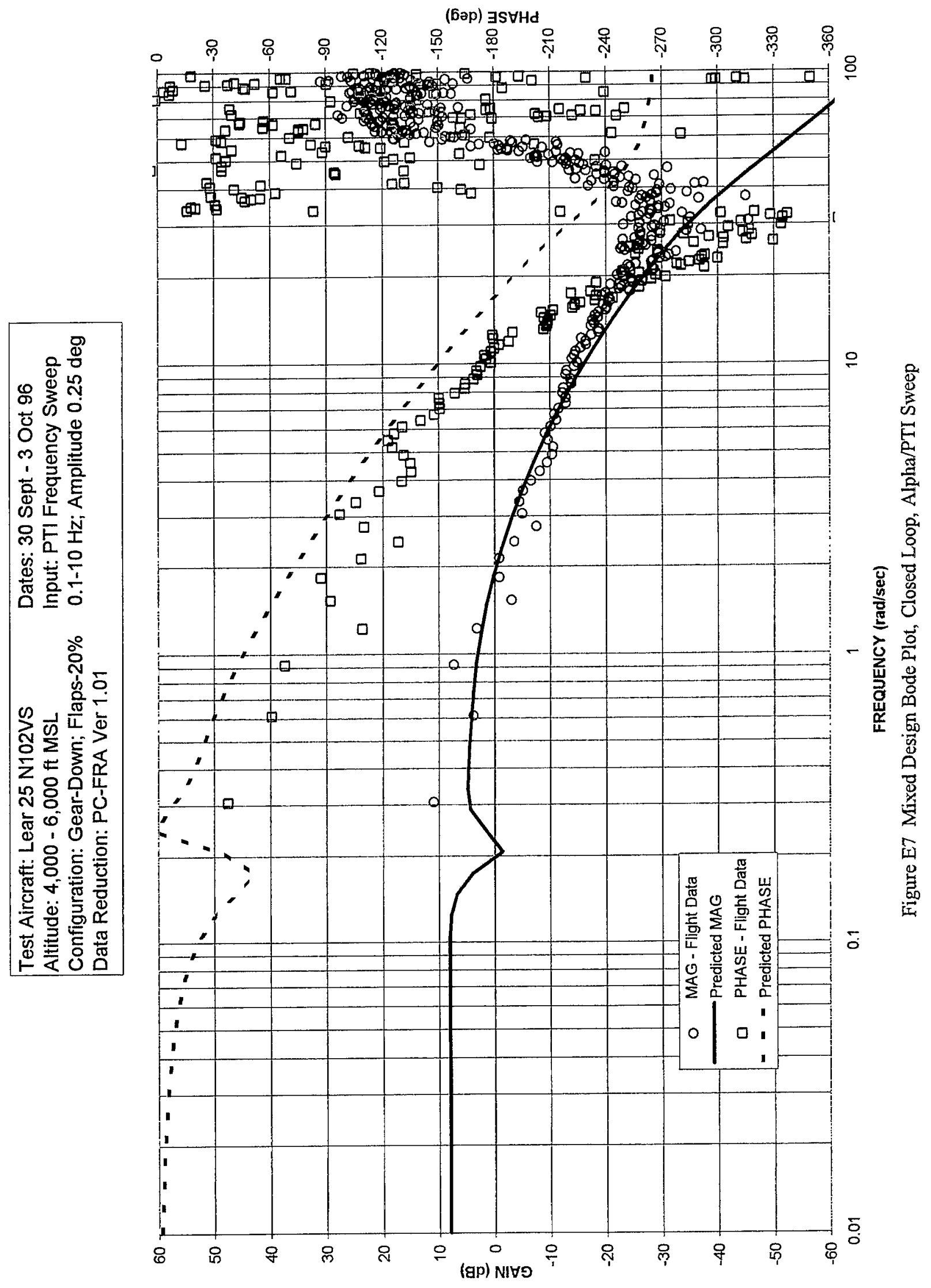




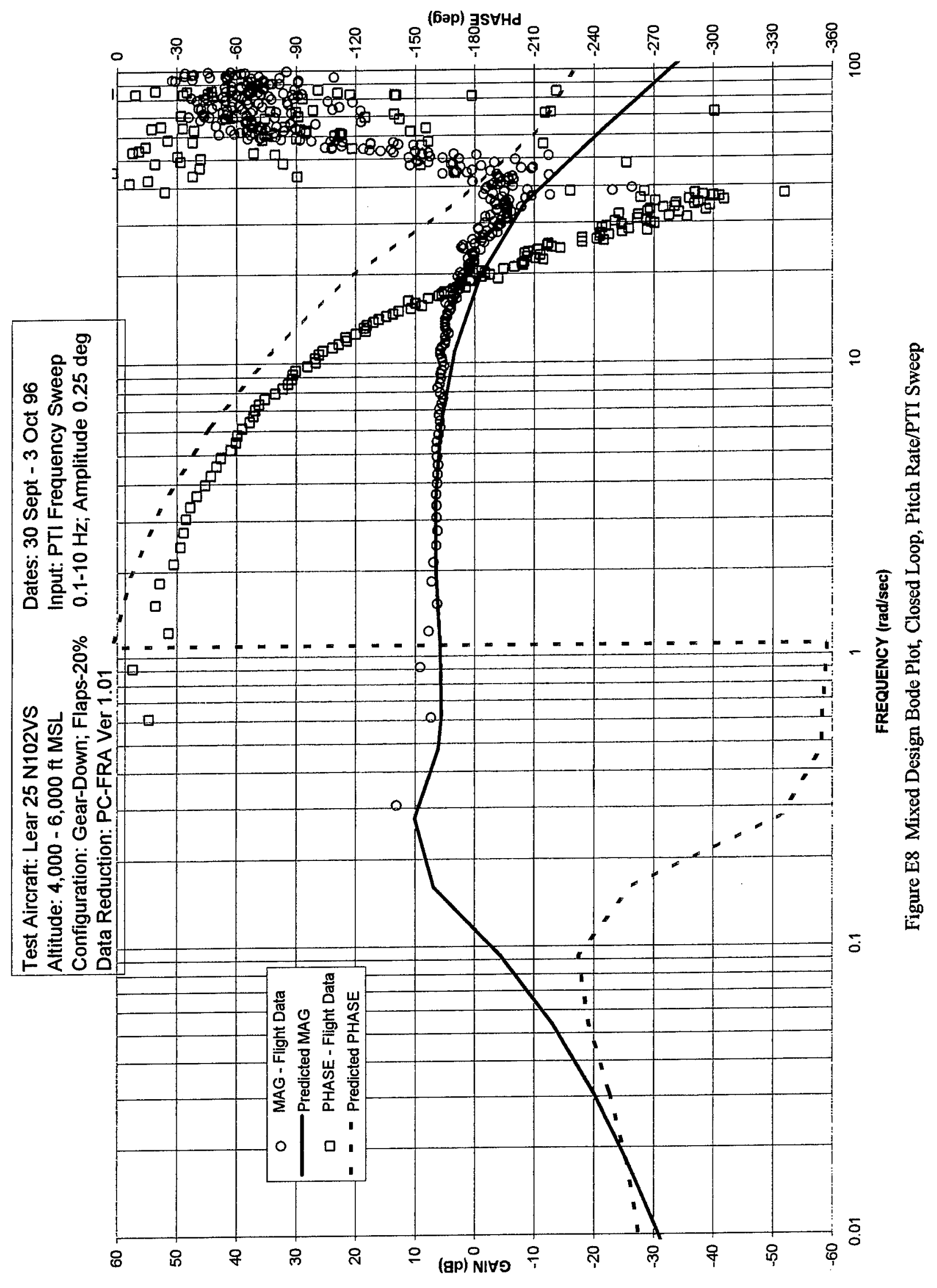


Test Aircraft: Lear 25 N102VS

Altitude: $4,000-6,000 \mathrm{ft} \mathrm{MSL}$

Configuration: Gear - Down; Flaps - $20 \%$
Date: 3 Oct 96

Input: Step, 1" stick displacement

- Flight Test Data

.... MATLAB Model Prediction
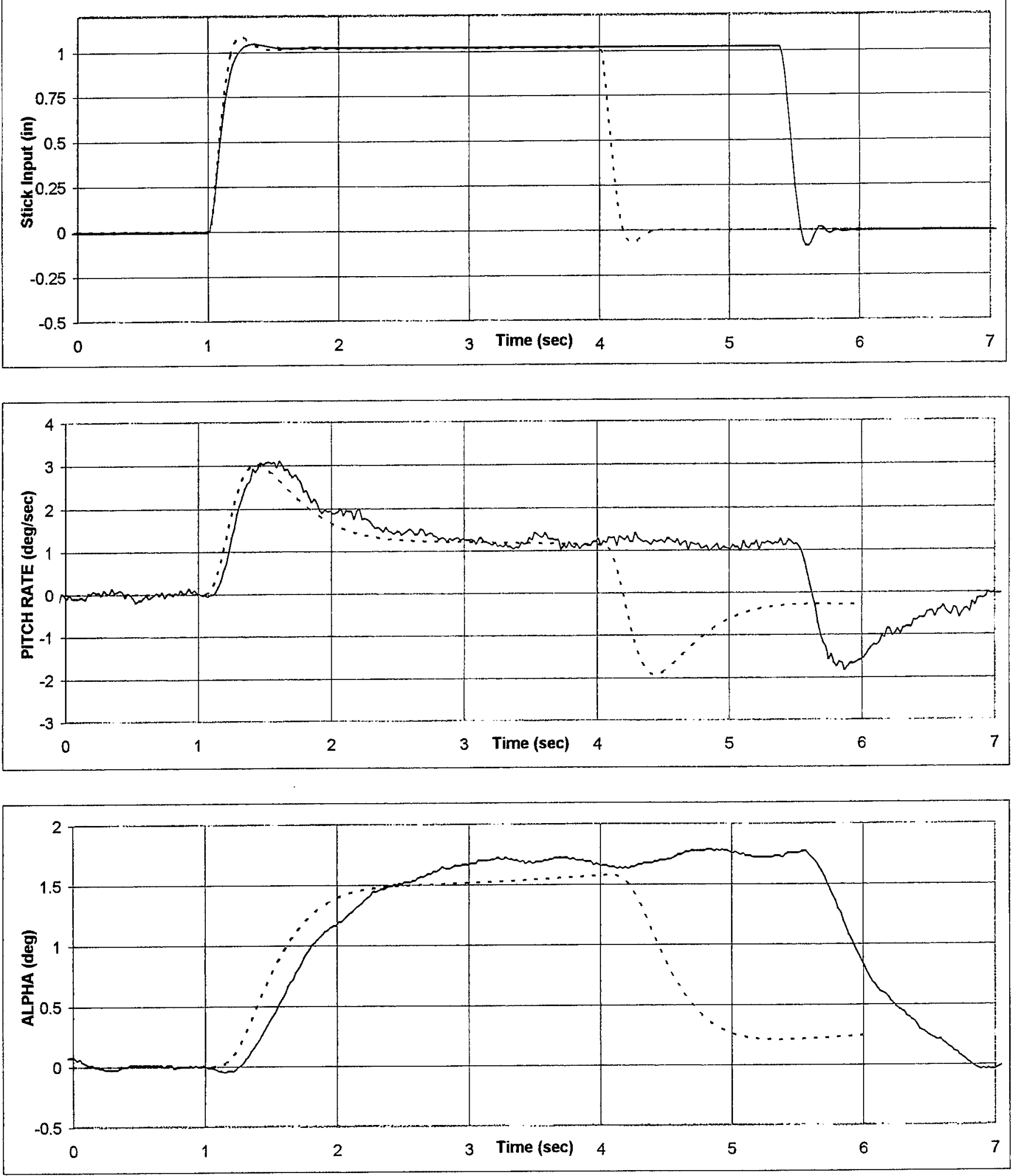

Figure E9 Step Input Time Histories, Classical Design 
Test Aircraft: Lear 25 N102VS

Altitude: $4,000-6,000 \mathrm{ft} \mathrm{MSL}$

Configuration: Gear - Down; Flaps - $20 \%$
Date: 3 Oct 96

Input: Step, 1" stick displacement

- Flight Test Data

... - MATLAB Model Prediction
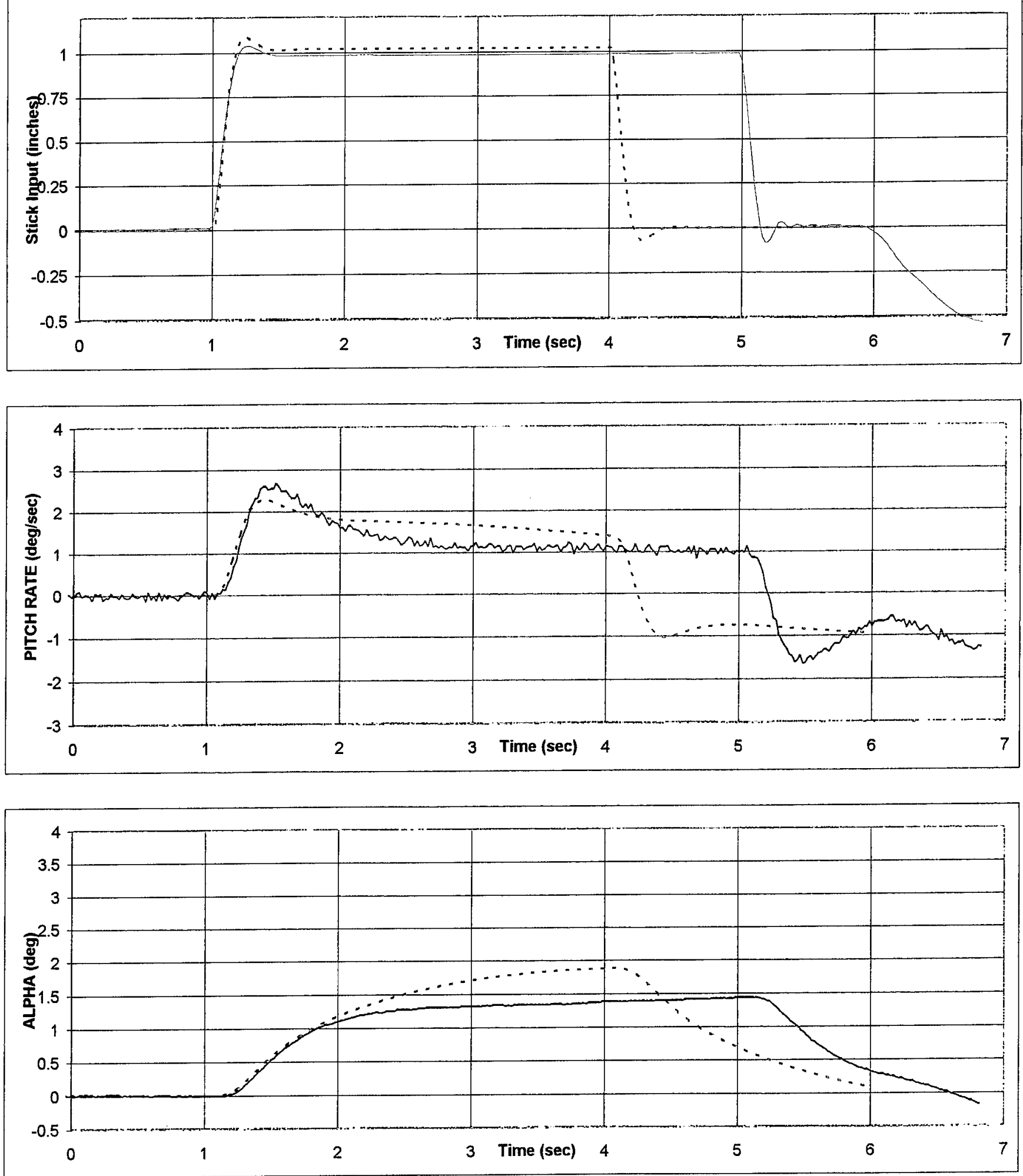

Figure E10 Step Input Time Histories, $\mathrm{H}_{2}$ Design 
Test Aircraft: Lear 25 N102VS

Altitude: $4,000-6,000 \mathrm{ft} \mathrm{MSL}$

Configuration: Gear - Down; Flaps - $20 \%$
Date: 3 Oct 96

Input: Step, 1" stick displacement

— Flight Test Data
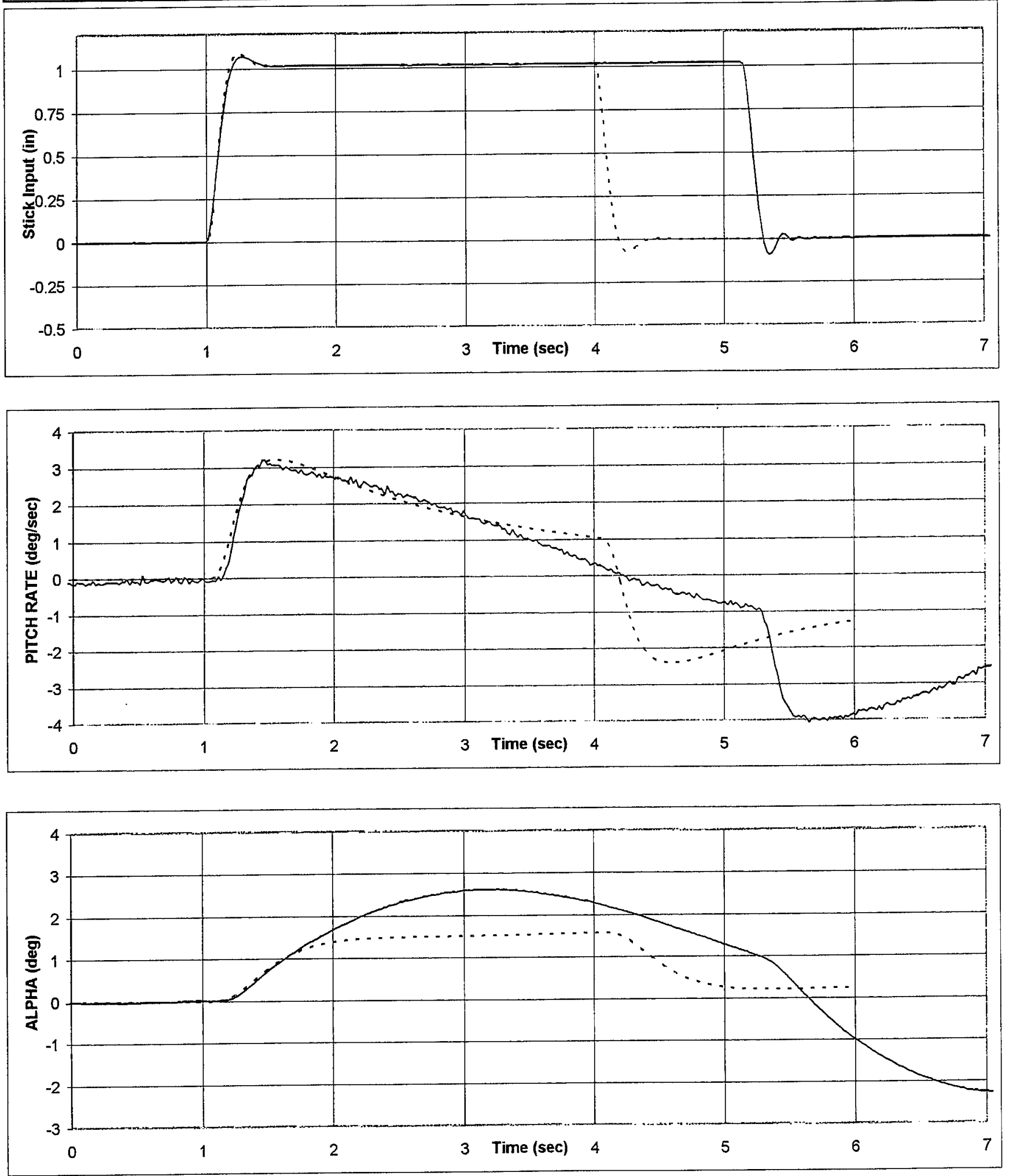

Figure E11 Step Input Time Histories, $\mathrm{H}_{\infty}$ Design 
Test Aircraft: Lear $25 \mathrm{~N} 102 \mathrm{VS}$

Altitude: $4,000-6,000 \mathrm{ft} \mathrm{MSL}$

Configuration: Gear - Down; Flaps - $20 \%$
Date: 3 Oct 96

Input: Step, 1" stick displacement

— Flight Test Data

.... MATLAB Model Prediction
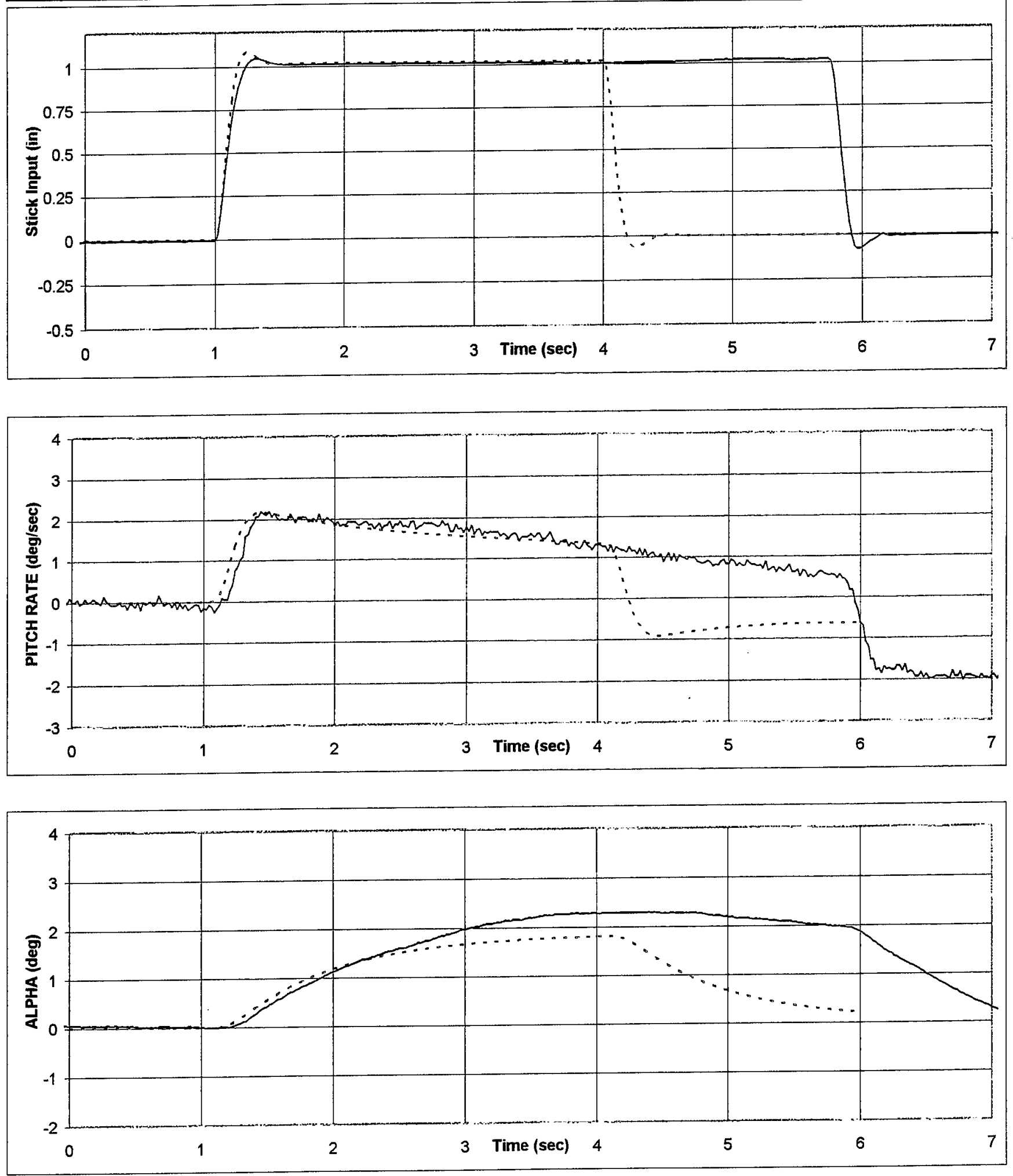

Figure E12 Step Input Time Histories, Mixed Design 
APPENDIX F

BLOCK DIAGRAMS 
This page intentionally left blank. 

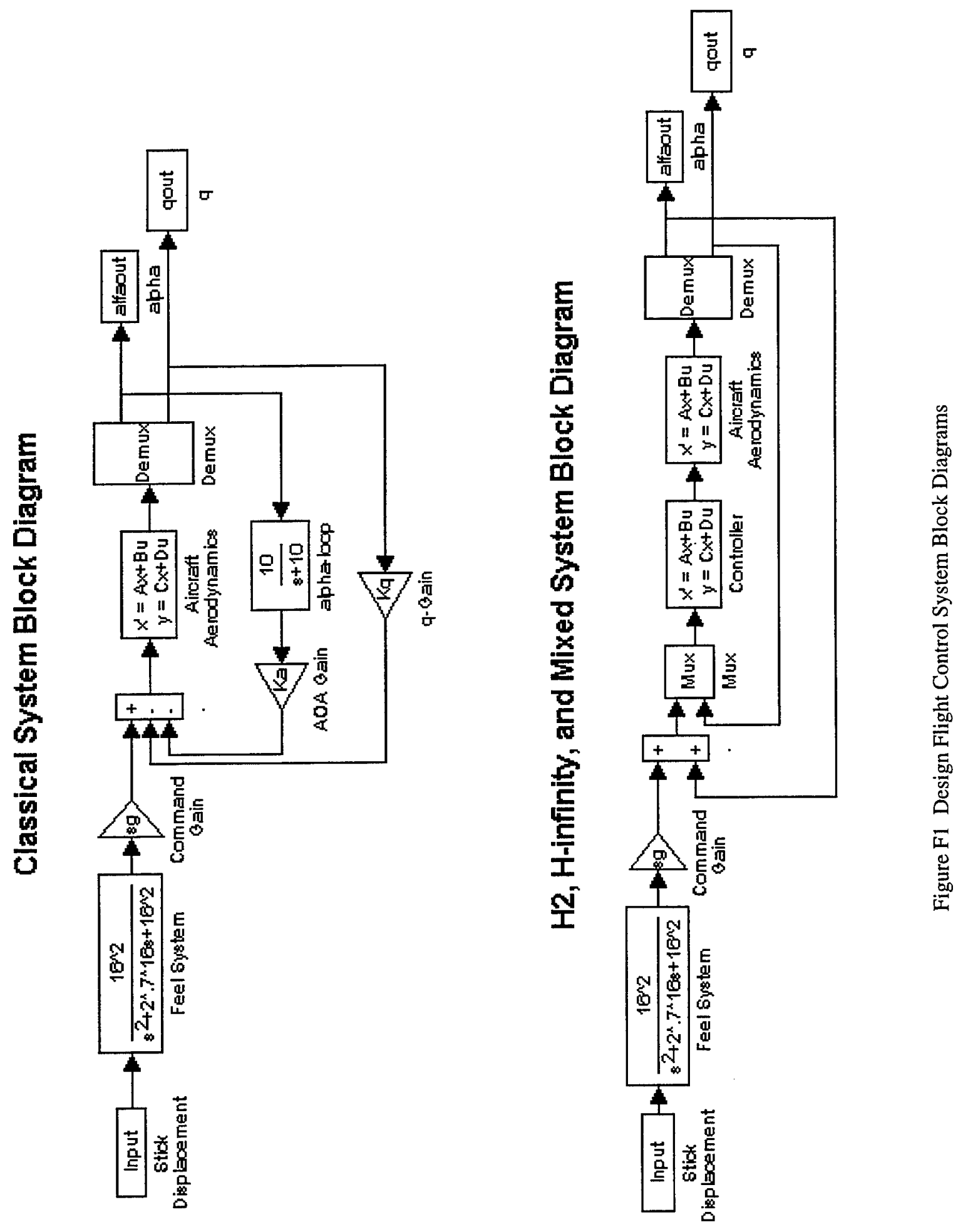



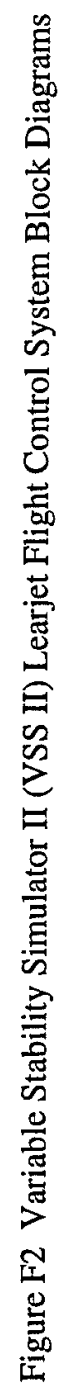




\section{LIST OF ABBREVIATIONS, ACRONYMS, AND SYMBOLS}

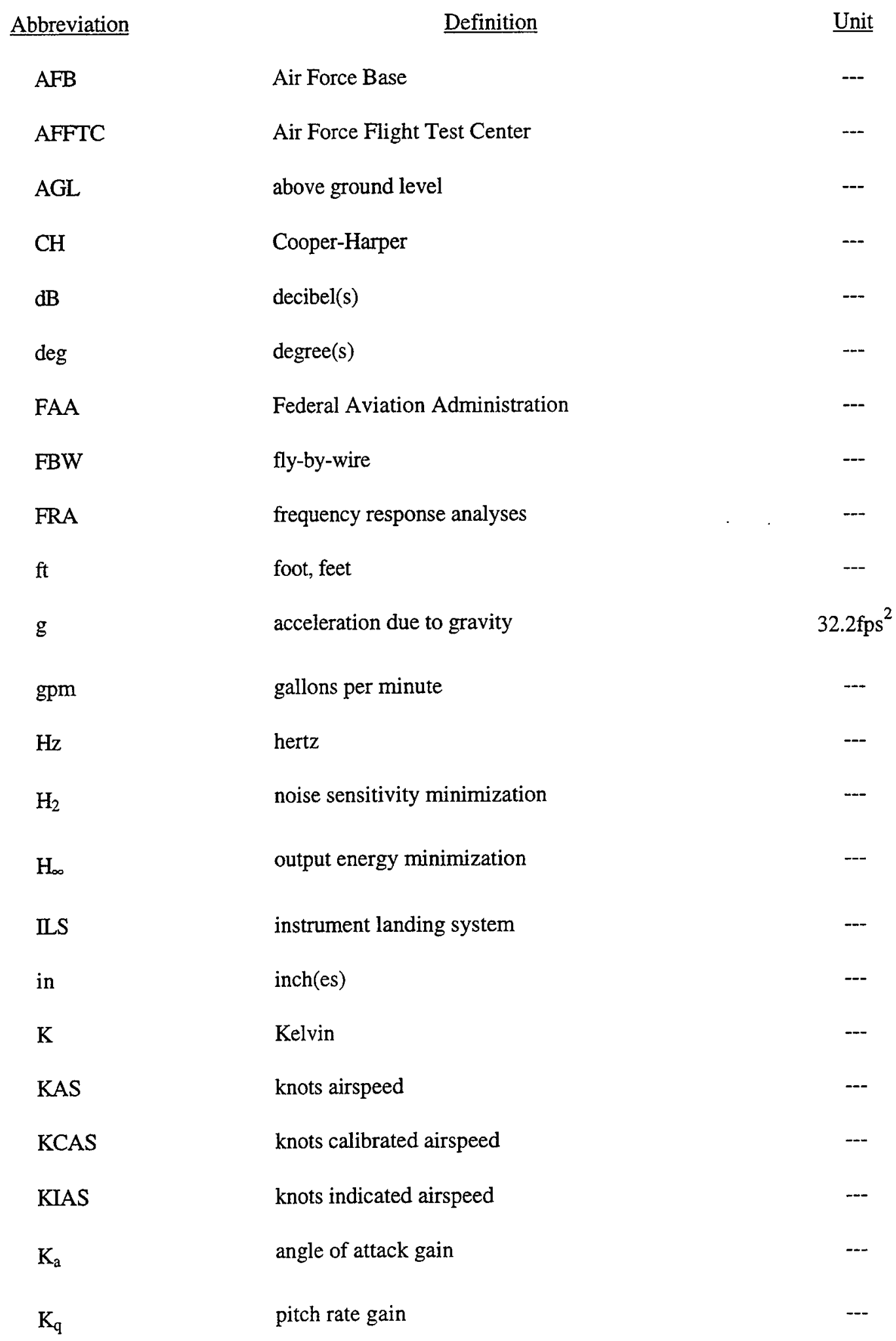




\section{LIST OF ABBREVIATIONS, ACRONYMS, AND SYMBOLS (Concluded)}

\begin{tabular}{|c|c|c|}
\hline Abbreviation & Definition & $\underline{\text { Unit }}$ \\
\hline $\mathrm{kt}$ & $\operatorname{knot}(\mathrm{s})$ & --- \\
\hline $\mathrm{lb}$ & pound(s) & $\cdots$ \\
\hline MIL-STD & military standard & -- \\
\hline MSL & mean sea level & -- \\
\hline No. & number & --- \\
\hline PC-FRA & personal computer-frequency response analyses & --- \\
\hline PIO & pilot induced oscillation & -- \\
\hline PTI & programmed test inputs & -- \\
\hline $\mathrm{q}$ & pitch rate & --- \\
\hline $\mathrm{rad} / \mathrm{sec}$ & radians per second & --- \\
\hline $\mathrm{S} / \mathrm{N}$ & serial number & --- \\
\hline$s$ & Laplace transform complex variable & --- \\
\hline $\sec$ & second(s) & - \\
\hline USAF & United States Air Force & $\cdots$ \\
\hline USN & United States Navy & -- \\
\hline VHF & very high frequency & - \\
\hline VSS $\Pi$ & Variable Stability Simulator II & -- \\
\hline
\end{tabular}




\section{DISTRIBUTION LIST}

Offsite Distribution

Number of Copies

Defense Technical Information Center

DTIC/OMI

8725 John J Kingman Rd, Suite 0944

Ft. Belvoir, VA 22060-6218

Flight Dynamics Directorate

Attn: Mr. Dave Leggett

Wright Laboratory

Air Force Material Command

Wright-Patterson AFB OH 45433-7562

Flight Research Division

Attn: Mr. Russ Easter

Calspan Corporation

P.O. Box 400

Buffalo, NY 14225

Onsite Distribution

USAF TPS/TS

$220 \mathrm{~S}$ Wolfe Ave

Edwards AFB CA 93524

USAF TPS/EDT

10

$220 \mathrm{~S}$ Wolfe Ave

Edwards AFB CA 93524

412 TW/TSF

195 E Popson Ave, Bldg 2750

Edwards AFB CA 93524-6843

412 TW/TSTL

305 E Popson Ave, Bldg 1400, Rm 110

Edwards AFB CA 93524-6630

AFFTC/HO

305 E Popson Ave, Bldg 1406

Edwards AFB CA 93524-6595

USAF TPS

Attn: Captain Phillip T. Edwards

$220 \mathrm{~S}$ Wolfe Ave

Edwards AFB CA 93524-6485 


\section{DISTRIBUTION LIST (Concluded)}

Onsite Distribution

$412 \mathrm{TW} / \mathrm{TSFF}$

Attn: Mr. Fred Webster

195 E Popson Ave, Bldg 2750

Edwards AFB CA 93524-6841

412 TW/TSFB

Attn: Mr. Bob Lee

195 E Popson Ave, Bldg 2750

Edwards AFB CA 93524-6841

412 TW/TSTL

307 E Popson Ave, Bldg 1400, Rm 110

Edwards AFB CA 93524-6630

AFFTC/HO

305 E Popson Ave, Bldg 1406

Edwards AFB CA $93524-6595$
Number of Copies

1

$\gamma$

1

3

1

Total

38 